\title{
Millennium-long summer temperature variations in the European Alps as reconstructed from tree rings
}

\author{
C. Corona ${ }^{1}$, J. Guiot ${ }^{1}$, J. L. Edouard ${ }^{2}$, F. Chalié ${ }^{1}$, U. Büntgen ${ }^{3}$, P. Nola $^{4}$, and C. Urbinati ${ }^{5}$ \\ ${ }^{1}$ CEREGE, UMR 6635 CNRS/Aix-Marseille Université, BP 80, 13545 Aix-en-provence cedex 4, France \\ ${ }^{2}$ IMEP, UMR 6116 CNRS/Aix-Marseille Université, BP 80, 13545 Aix-en-provence cedex 4, France \\ ${ }^{3}$ Swiss Federal Research Institute WSL Zuercherstrasse 1118903 Birmensdorf, Switzerland \\ ${ }^{4}$ Univ. degli Studi di Pavia, Dip. Ecologia del Territorio a degli Ambienti Terrestri, Via S. Epifanio, 14, 27100 Pavia, Italy \\ ${ }^{5}$ Univ. Politecnica delle Marche, Dip. SAPROV, Forest Ecology and Management, Via Brecce Bianche, 60131 Ancona, Italy
}

Received: 8 August 2008 - Published in Clim. Past Discuss.: 7 October 2008

Revised: 3 June 2010 - Accepted: 9 June 2010 - Published: 25 June 2010

\begin{abstract}
This paper presents a reconstruction of the summer temperatures over the Greater Alpine Region (44.05 $\left.47.41^{\circ} \mathrm{N}, 6.43^{\circ}-13^{\circ} \mathrm{E}\right)$ during the last millennium based on a network of 38 multi-centennial larch and stone pine chronologies. Tree ring series are standardized using an Adaptative Regional Growth Curve, which attempts to remove the age effect from the low frequency variations in the series. The proxies are calibrated using the June to August mean temperatures from the HISTALP high-elevation temperature time series spanning the 1818-2003. The method combines an analogue technique, which is able to extend the too short tree-ring series, an artificial neural network technique for an optimal non-linear calibration including a bootstrap technique for calculating error assessment on the reconstruction. About $50 \%$ of the temperature variance is reconstructed. Low-elevation instrumental data back to 1760 compared to their instrumental target data reveal divergence between (warmer) early instrumental measurements and (colder) proxy estimates. The proxy record indicates cool conditions, from the mid-11th century to the mid-12th century, related to the Oort solar minimum followed by a short Medieval Warm Period (1200-1420). The Little Ice Age (1420-1830) appears particularly cold between 1420 and 1820 with summers that are $0.8^{\circ} \mathrm{C}$ cooler than the $1901-$ 2000 period. The new record suggests that the persistency of the late 20th century warming trend is unprecedented. It also reveals significant similarities with other alpine reconstructions.
\end{abstract}

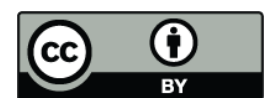

Correspondence to: C. Corona (christophe.corona@gmail.com)

\section{Introduction}

In the last decade, many studies concerned past temperature variations in the Greater Alpine Region (GAR). They are based on long instrumental observations (Begert et al., 2005; Brunetti et al., 2006; Auer et al., 2007), written historical documents (Pfister, 1999; LeRoy Ladurie 2004), glacier front elevation (Holzhauser et al. 2005; Oerlemans 2005) or multiproxy combinations (Casty et al., 2005, for example). Regarding dendroclimatological studies, the Alps are favoured by several low-elevation instrumental series extending to the mid-18th century and by some high-elevation ones to the early 19th century (Auer et al., 2007). This enables calibration and independent verification of tree-ring proxy to instrumental target data over exceptionally long periods (Frank and Esper 2005; Büntgen et al., 2008). To date, numerous temperature reconstructions have been produced from local treering chronologies and regional-scale network compilations (see references herein). However, most of them span the last 300-500 years only. There are relatively few that extend back prior to 1000 (all dates in this paper are given in calendar years AD). To date and to our knowledge, there are only two tree ring-based Alpine temperature reconstructions that extend back prior to 1000 and forward into the 21 st century (Büntgen et al., 2005, 2006a). This is because of the scarcity of wood material from the early part of the last millennium, necessary to assess climate variations during the putative Medieval Warm Period (MWP) (Lamb, 1976). In contrast, much more evidence of a Little Ice Age (LIA) cooling is reported from various sites and archives (Grove, 1988). Büntgen et al. (2005, 2006a) published two mean summer (JuneAugust and June-September) temperature reconstructions

Published by Copernicus Publications on behalf of the European Geosciences Union. 
based on tree-ring width (TRW) and maximum latewood density (MXD) from tree-ring sites in Switzerland and Austria. These reconstructions are the longest available for the Alps (951-2002 and 755-2004).

In this paper, we present a millennium-long summer temperature reconstruction covering most of the Alpine arc by various existing and newly updated composite dataset that combine living trees with dendroarchaeological material. Unlike previous reconstruction, our reconstruction is built from series widely distributed in the Alpine arc, and, in particular, series from Western Alps are incorporated in the dataset. In an effort to capture the natural range of high- to low- frequency temperature variations and to provide a refined reconstruction of their amplitude over past millennium, we combined version of the well-established RCS technique for tree-ring detrending, an analog method for data aggregation, and a neural network approach for reconstruction (Guiot et al., 2005). This approach has been applied successfully in palaeoclimatology (Peyron et al., 1998; Guiot et al., 2005) and in dendroclimatology (Guiot and Tessier, 1997; Keller et al., 1997; Carrer and Urbinati, 2005). It differs from linear statistical methods in that it introduces non-linearity to the system and appears particularly adapted to tree-ring based reconstructions due to the complexity of tree growth, dependent on climate but also on time, tree geometry and other factors. Results are compared to existing alpine reconstructions, and comparison with $\mathrm{NH}$ reconstructions is conducted to place our regional reconstruction in a larger-scale context.

\section{Material}

\subsection{Tree-ring data}

We have collected a large compilation of living and historic wood samples from numerous well-distributed, highelevation wood samples in the European Alps. The data extracted from the DENDRODB relational European treering database (http://dendrodb.cerege.fr/) and the WDC tree-ring database (http://www.ncdc.noaa.gov/paleo/treering. html) have been supplemented with new and unpublished multi-centennial-long pine and larch chronologies (Edouard, unpublished chronologies). In total, 502 larch series (Larix decidua Mill., 19 sites) and 463 stone pine series (Pinus cembra L., 17 sites) have been used (Table 1). For the larch collection, the precise number of trees concerned by these series is, however, not clearly specified, as some of the historical timbers might originate from the same trees (Büntgen et al., 2006b). In contrast, each pine represents a single tree. Two composite chronologies (Swiss1 and Swiss2) are also integrated. Swiss1 (TRW) is a Regional Curve Standardized (RCS) chronology, including four larch composite chronologies (1110 TRW series) from Switzerland and the most recent part of a 7000-year pine TRW chronology (417 ring width series) from western Austria (Büntgen et al., 2005). "Swiss 2" (MXD) is composed of 180 maximum latewood density (MXD) larch measurement series from 86 living trees and 94 historic timbers deriving from elevations $>1600 \mathrm{~m}$ a.s.l. located in the sub-alpine Lötschental, Simplon and Aletsch regions (Büntgen et al., 2006a). All these chronologies are more than 400 years long. Three larch chronologies ("Merveilles", "Swiss1" and "Swiss2") are covering the whole last millennium. The "Nevache Granges" larch chronology covers the last millennium with a gap between AD 1255 and AD 1384. Characteristics of these chronologies are detailed in Table 1.

\subsection{Climatic data}

Our aim is to provide reliable palaeoclimatic evidence for the period before AD 1818, when systematically homogenized high-elevation instrumental station measurements started recording in the Greater Alpine Region (GAR) (HISTALP; Auer et al., 2007). The HISTALP high-elevation temperature data derive from 13 individual stations located $>1500 \mathrm{~m}$ a.s.l. and cover the $45^{\circ}-47^{\circ} \mathrm{N}$ and $6^{\circ}-9^{\circ} \mathrm{E}$ area along the main Alpine crest-line. This compilation thus best represents the spatial area and the elevation-zone of the treering network.

The HISTALP low-elevation $(<1500 \mathrm{~m}$ a.s.l. $)$ temperature time series (Auer et al., 2007) back to 1760 derives from 118 stations across the GAR. It is herein used for extra verification and to characterize potential limitations of our reconstruction in preserving long-term trends as those reported from the transition of the LIA cooling until the most recent warming. Correlation (1818-2003) between the June-August (JJA) mean from high- and low-elevation is 0.92 , indicating that these two series display a similar history. Temperatures are expressed as anomalies with respect to the 1901-2000 mean.

\section{Methods}

First, the tree-ring width series are detrended using an Adaptive Regional Growth Curve (ARGC) (Nicault et al., 2008, 2010), which preserves long-term trends in the resulting chronologies. Secondly, an analogue technique is used to expand all series to the common 1000-2000 period. Thirdly, an Artificial Neural Network (ANN) technique (referred to here as a transfer function) is calibrated on the 1818-2000 period and then applied to the individual site chronologies back to AD 1000. Five calibration and validation tests are finally carried out to assess the reliability of the reconstruction.

\subsection{Tree-ring data detrending and chronology development}

Cook et al. (1995) demonstrated that methods of individual series detrending result in a lose of potential longer-term climatic information above the segment length. Mean segment 
Table 1. Characteristics of the tree-ring sites: identifier (No), site name (TRW: Tree Ring Width, MXD: Maximum Latewood Density), location, species (LADE: Larix decidua; PICE : Pinus cembra), period covered before truncation due to low replication (see details in Sect. 3.1), number of individual tree-ring width series ( $n$ ), Mean Serie Length (MSL in years), Average Growth Rate (AGR in 1/100 mm/year) and source (DENDRODB: http://servpal.cerege.fr/webdbdendro; WDC: http://www.ncdc.noaa.gov/paleo/treering.html). The identifiers are the same as in Fig. 1.

\begin{tabular}{|c|c|c|c|c|c|c|c|c|c|c|}
\hline No & Site & Species & $\begin{array}{l}\text { Longitude } \\
\text { (E) }\end{array}$ & $\begin{array}{l}\text { Latitude } \\
(\mathrm{N})\end{array}$ & $\begin{array}{l}\text { Altitude } \\
\text { (m a.s.l.) }\end{array}$ & $\begin{array}{l}\text { Period } \\
\text { (AD) }\end{array}$ & $n$ & MSL & AGR & Source \\
\hline 1 & Aleve & LADE & $7^{\circ} 04$ & $44^{\circ} 36$ & 2200 & $1426-1997$ & 12 & 400 & 51.6 & Nola P., DENDRODB \\
\hline 2 & Alpe Musella & LADE & $9^{\circ} 51$ & $46^{\circ} 17$ & 2200 & 1563-1992 & 16 & 143 & 97.6 & Nola P., DENDRODB \\
\hline 3 & Berchtesgaden & LADE & $13^{\circ} 01$ & $47^{\circ} 24$ & 1725 & $1380-1947$ & 27 & 163 & 33.2 & Brehme K., WDC \\
\hline 4 & Cadini Lago di Misurina & LADE & $12^{\circ} 15$ & $46^{\circ} 34$ & 2000 & $1463-1998$ & 17 & 283 & 68.3 & Urbinati C., DENDRODB \\
\hline 5 & Chalets de l'Orgère & LADE & $6^{\circ} 40$ & $45^{\circ} 12$ & 2100 & $1353-1973$ & 26 & 335 & 83.6 & Tessier L., DENDRODB \\
\hline 6 & Chardonnet & LADE & $6^{\circ} 32$ & $45^{\circ} 01$ & 2180 & $1492-1989$ & 18 & 331 & 67.9 & Edouard J.-L., unpublished \\
\hline 7 & Clapouse & LADE & $6^{\circ} 25$ & $44^{\circ} 51$ & 2150 & $1557-1995$ & 14 & 289 & 60.8 & Guibal F., DENDRODB \\
\hline 8 & Comasine & LADE & $10^{\circ} 39$ & $46^{\circ} 20$ & 2200 & $1438-1999$ & 17 & 447 & 69.1 & Urbinati C., DENDRODB \\
\hline 9 & Fodara Vedla Alm & LADE & $12^{\circ} 03$ & $46^{\circ} 22$ & 1970 & $1520-1990$ & 69 & 140 & 10.2 & Huesken W., DENDRODB \\
\hline 10 & Freyssinières & LADE & $6^{\circ} 29$ & $44^{\circ} 42$ & 2150 & $1474-1992$ & 21 & 317 & 75.8 & Edouard J.-L., unpublished \\
\hline 11 & Merveilles & LADE & $7^{\circ} 26$ & $44^{\circ} 02$ & 2200 & 988-1974 & 28 & 448 & 36.8 & Tessier L., DENDRODB \\
\hline 12 & Moutieres & LADE & $6^{\circ} 50$ & $44^{\circ} 17$ & 2100 & $1414-1995$ & 34 & 395 & 68.3 & Edouard J.-L., unpublished \\
\hline 13 & Muestair & LADE & $10^{\circ} 26$ & $46^{\circ} 36$ & - & $1295-1905$ & 17 & 78.4 & 15.7 & Schweingruber F. H., WDC \\
\hline 14 & Névache Granges & LADE & $6^{\circ} 34$ & $45^{\circ} 01$ & 2000 & $751-1894$ & 88 & 159 & 63.1 & Edouard J.-L., unpublished \\
\hline 15 & Obergurgl & LADE & $11^{\circ} 01$ & $46^{\circ} 31$ & - & $1333-1974$ & 35 & 182 & 14.8 & Giertz V., DENDRODB \\
\hline 16 & Oriol & LADE & $6^{\circ} 35$ & $44^{\circ} 47$ & 2180 & 1381-1989 & 19 & 445 & 63.1 & Edouard J.-L., unpublished \\
\hline 17 & Passo Cinque Croci & LADE & $10^{\circ} 34$ & $46^{\circ} 10$ & 2050 & $1468-1999$ & 15 & 220 & 87.4 & Urbinati C., DENDRODB \\
\hline 18 & Ravin de Congerman & LADE & $6^{\circ} 39$ & $44^{\circ} 06$ & 2100 & $1421-1992$ & 8 & 338 & 62.9 & Tessier L., DENDRODB \\
\hline 19 & Ventina & LADE & $9^{\circ} 46$ & $46^{\circ} 18$ & 2050 & $1007-1993$ & 21 & 441 & 57.8 & Nola P., DENDRODB \\
\hline
\end{tabular}

length (MSL: the average number of rings per sample) and Average Growth Rate (AGR : the length of core or the radius of disc sample divided by the number of rings) indicated in Table 1 are useful for determining the maximum resolvable low-frequency variance in a tree-ring chronology due to climate after its individual ring-width series have been detrended.

Our method is adapted to the Regional Curve Standardisation (RCS) method (Becker et al., 1989; Briffa et al., 1992). This age-related detrending method enables to preserve inter-annual to multi-centennial information in the resulting chronologies. All measurement series are first aligned according to their cambial age of one (biological zero). The mean of all age-aligned series is calculated and the so-called Regional Curve (RC) is usually smoothed with a cubic spline or a parametric curve. In Alpine regions, as in many other heterogeneous regions, rapid variations in soil factors, microclimate, competition, and other factors governing site productivity, may induce major differences in tree growth rates. The outlier sites, i.e. those that show a trend substantially different from the regional curve, may then induce strong bias in RCS chronology. In such conditions, a theoretical growth curve that can be generalized for all the sites of a given species in a given area is particularly difficult to process. In order to minimize any bias introduced into the index series by differences in growth rates, we calculate a growth curve for each tree. The method is called the Adaptative Regional Growth Curve (ARGC) (Nicault et al., 2008, 2010). The ARGC theoretical growth curve, needed to detrend a specific tree-ring series, is supposed as a non-linear function of cambial age and tree productivity, which is a function of competition or soil. Following Rathgeber et al. (1999), we take into account the juvenile growth calculated on the first 50 years to reflect the tree productivity related to the site conditions. The tree-growth trend is then modelled by a 3parameter-equation:

$\Upsilon_{t}=F\left(\alpha\left(C_{t}\right), g(C), G(C)\right)$.

Where $\Upsilon_{t}$ is the theoretical value for tree-ring $C_{t}, \alpha\left(\mathrm{C}_{t}\right)$ is the age of tree-ring $C_{t}, g(C)$ is the initial growth of tree $C$, 
Table 1. Continued.

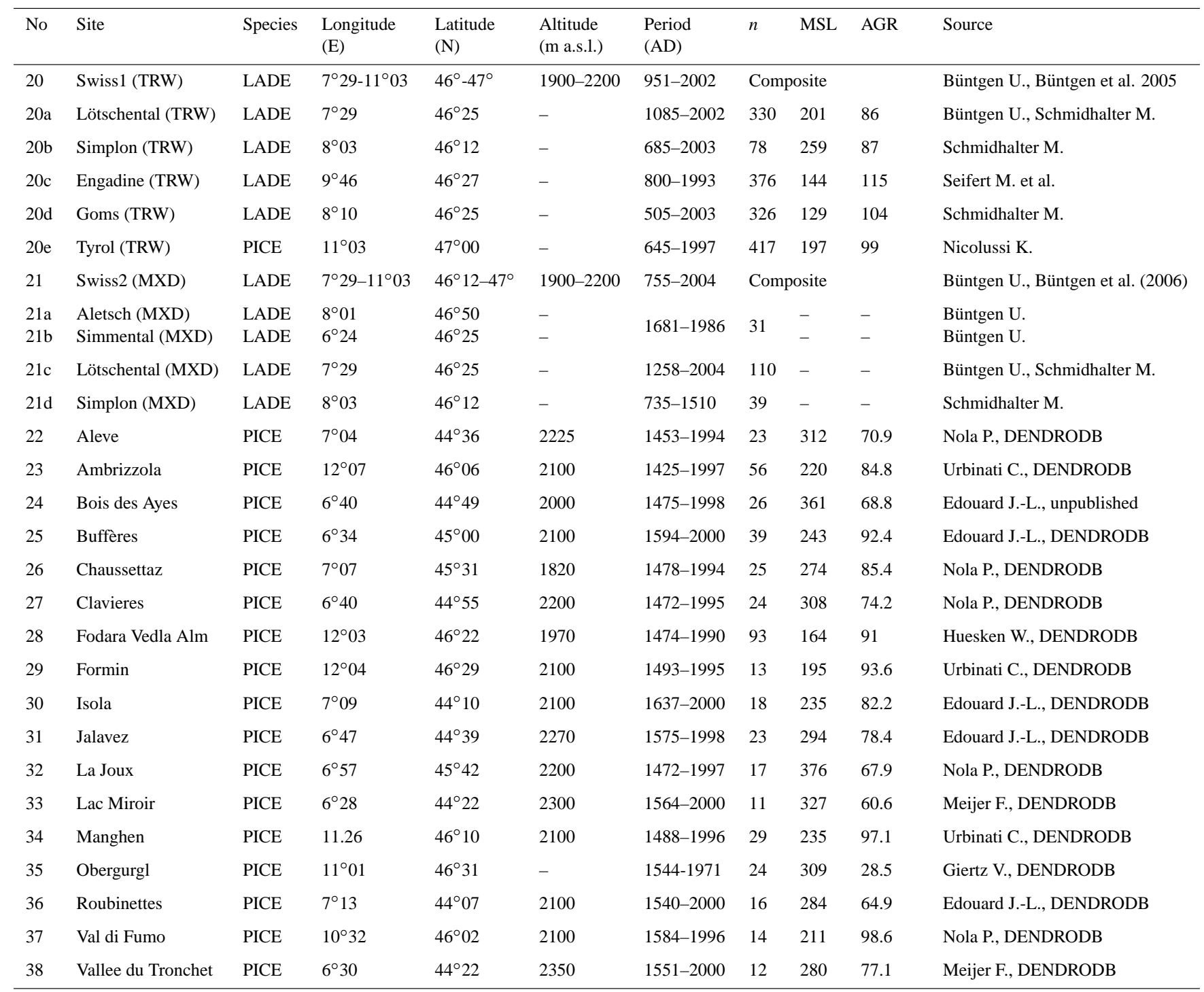

i.e. the average of the first 10 rings, $G(C)$ is the maximal juvenile growth of tree $C$, i.e. the maximum value reached during its juvenile stage (first 50 years) after smoothing using a 10 -yr window.

An ANN technique as introduced by Nicault et al. (2010) is used to estimate $\mathrm{F}$ for each tree (Eq. 1). The tree-ring series are indexed by dividing each measured ring by its expected value estimated from this curve. Finally, the standardized tree-ring indices are averaged on the site-level. As each tree is fitted by the ANN, the detrending is not sensitive to the occurrence missing rings at the tree pith (Nicault et al., 2010). Resulting chronologies are truncated at a minimum replication of three series. Due to a high degree of common variance between the larch and pine chronologies (see Sect. 4.1), these data were simply merged yielding to increased sample size and thus more robust time-series allowing further analysis to be applied.

\subsection{The analogue technique}

Considering the fact that the number of available proxies decreases back in time, several authors (Mann et al., 1999; Luterbacher et al., 2002; Xoplaki et al., 2005; Casty et al., 2005; Pauling et al., 2006) have used a number of regressions based on a decreasing number of proxies or nested component regression models (Cook et al., 2002). Resulting reconstructions are often still contaminated by artificial variances changes through time (Frank et al., 2007b) which are 
Table 2. Correlation matrix of the Adaptative Regional Growth Curve detrended chronologies (1637-1974 period).

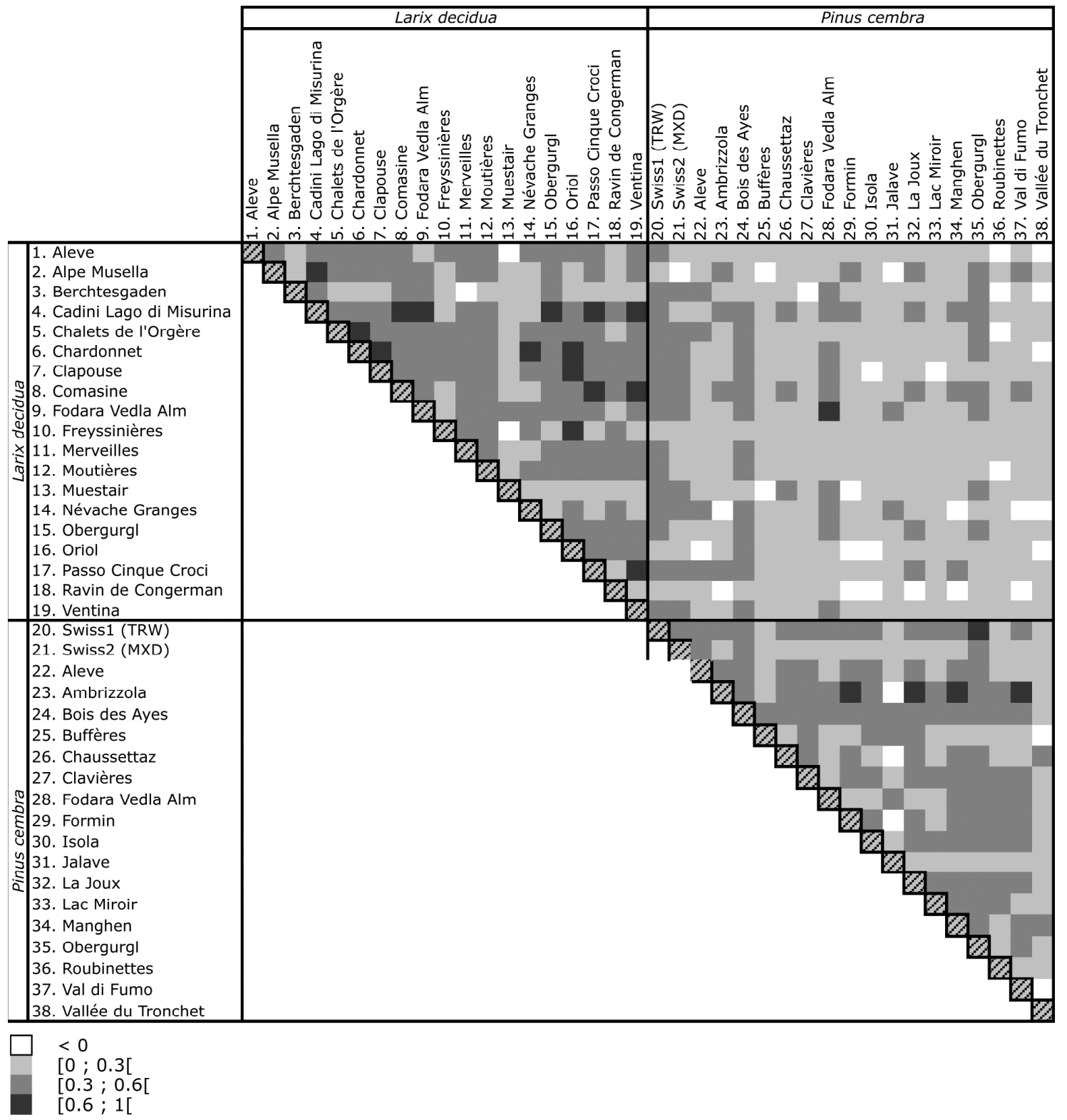

an inverse function of the number of proxies used. Moreover, such methods do not account for missing values within proxy series. A more and more frequently used alternative is the regularized expectation maximization (REGEM), which imputes missing values on the basis of the regression between variables (Schneider, 2001), in a manner that make optimal use of spatial and temporal information in the dataset. Here, infilling of missing data is done using an analogue technique introduced by Guiot et al. (2005). This technique has not the same weakness as REGEM, as the number of predictors is maintained constant in time. In order to replace a missing year for any given tree ring series, we compared the existing vector of data with all other series available during this time on the basis of the Euclidian distance and not on the basis of the correlation between variables, as most of the methods do. The corresponding year from the eight nearest series (called analogues) are averaged with a weight inversely proportional to the distance, providing the estimate of the missing treering value. The number of analogues varies according to the data available, but those are used with a distance lower than 0.5 . Note that some missing values may remain, if there are not enough data for that period or if there are no close enough analogues. The quality of the fit is estimated with the correlation between observations and estimates on the common 


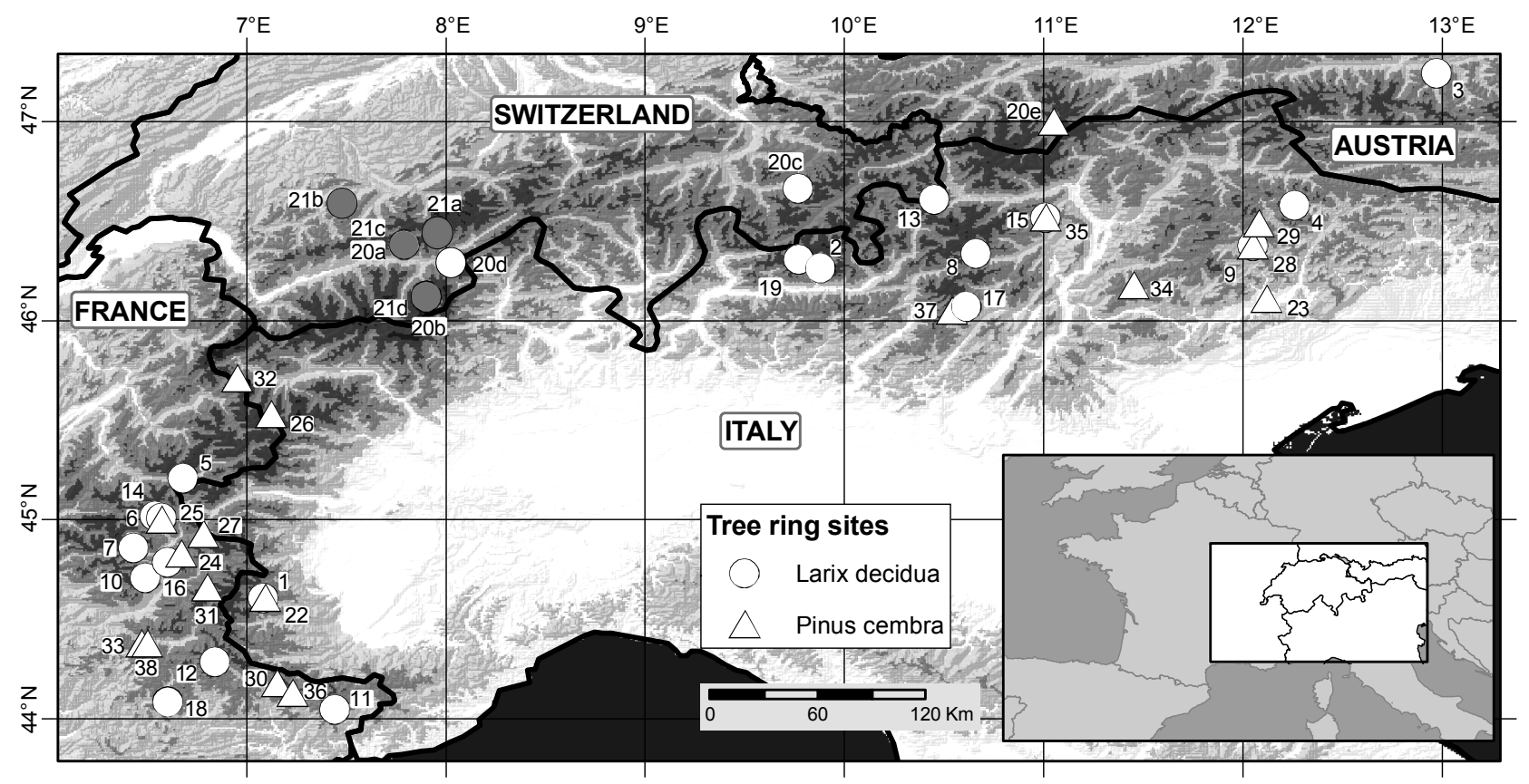

Fig. 1. Location map of the 38 tree-ring sites used for the Alpine temperature reconstruction. Sites are differentiated by species and whether ring-width and maximum latewood density parameters were both available for a site (grey symbol) or only ring-width (white symbol). All tree-ring sites are above $1700 \mathrm{~m}$ a.s.l. The labelled numbers also refer to Table 1.

period. A good correlation proves that the hypothesis justifying the use of analogues is satisfied. Finally, if estimated series have a standard deviation inferior by $20 \%$ to the original series, the estimates are rescaled to keep the same variance. This method allows us to expand all series to the same common 1000-2000 period using only a single transfer function. Results will show below that the method has an interesting characteristic as compared with the regression based methods: the correlations between estimated series are not better than those of the observed series as the estimation process is not based on the similarity between variables but between the years. The method is then conservative for the observed spatial variability. Moreover, it has been demonstrated that variance is well maintained independent of the number of predictors (Nicault et al., 2008).

\subsection{Calibration and verification}

Standardized and completed tree-ring series were transformed into a smaller number of principal component analysis (PCA Richman, 1986) in order to remove the correlation between the regressors and to provide more robust estimates. We have successively tested the inclusion of 10 to 19 principal components to select principal component truncation criteria. These principal components were then related to several combinations of regressors on the 1818-2000 period using the same ANN technique above mentioned. The best calibration was obtained when calibrating with JJA temper- atures anomalies in accordance with the positive responses of Pinus cembra and Larix decidua to summer temperatures observed, by several authors (e.g. Frank and Esper, 2005), at high altitude in the Alps. The anomalies of the JJA temperatures during the last 1000 years were estimated by applying the ANN to the principal components. To avoid loss of amplitude due to imperfect calibration, simple scaling of the reconstruction against instrumental targets, that is adjusting the variance, was applied.

To assess the reliability of the ANN, a bootstrap method (Efron, 1979; Guiot, 1990) was used. A subset of the observed data (principal components and temperature) was randomly extracted with replacement. The ANN was then calibrated on this data subset. This is iterated 50 times. At each calibration, a determination coefficient $\left(R^{2}\right)$ between estimated and observed values was calculated for the data randomly taken for the calibration (the calibration $R$-squared, $R^{2} \mathrm{C}$ ), and another one was calculated for the remaining data (the verification $R$-squared, $R^{2} \mathrm{~V}$ ).

The reconstruction skill and robustness are assessed by the Root Mean Squared Error of the calibration data (RMSE), the Root Mean Squared Error of Prediction of the verification data (RMSEP), the Reduction of Error statistic (RE) and the Coefficient of Efficiency (CE), both on the verification data (Wigley et al., 1984). The RMSE statistic tests the quality of fit on the calibration data, while the RMSEP test the prediction capacity of the transfer function by using independent data. The RE statistic ranges from minus infinity 


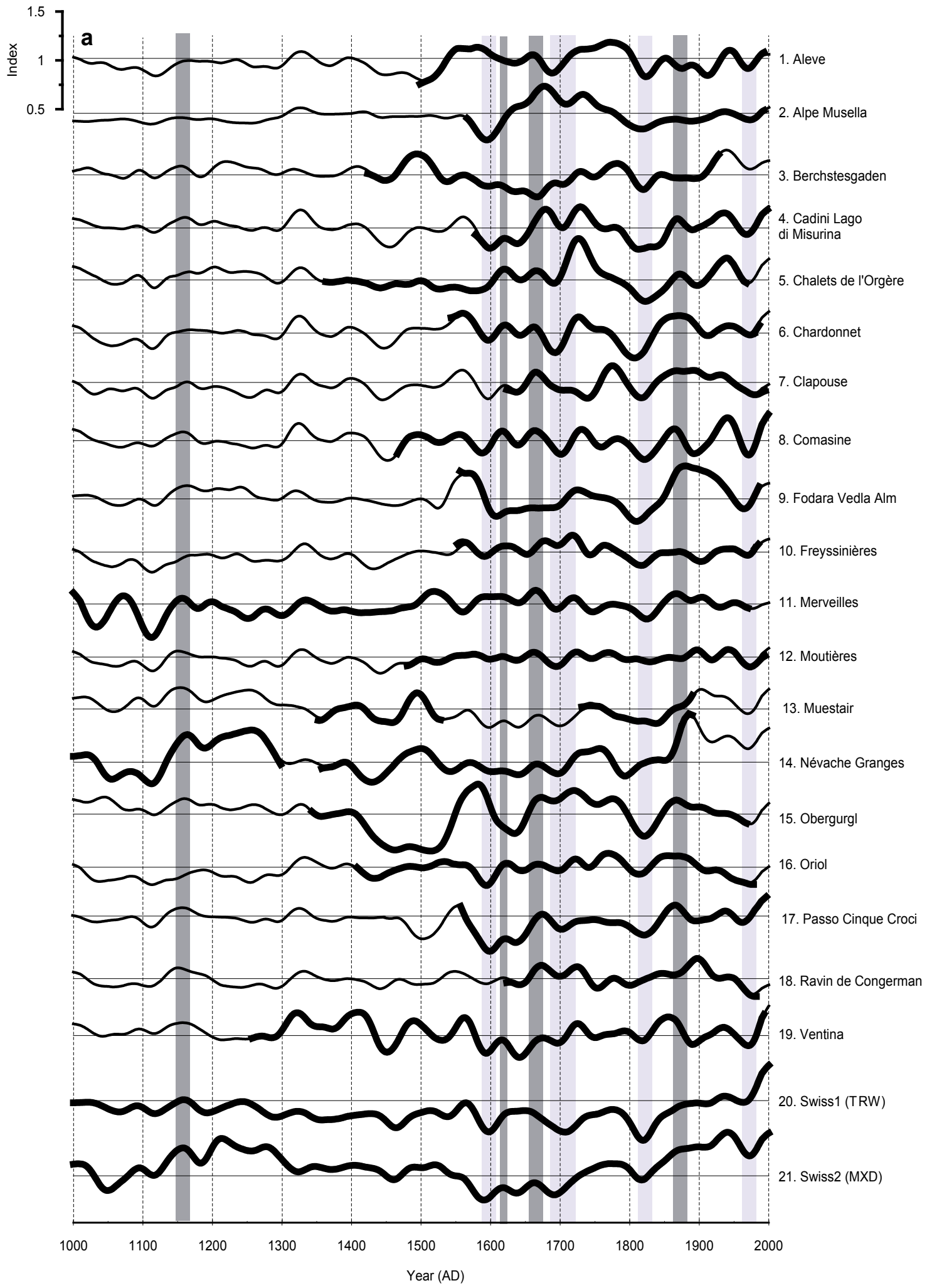

Fig. 2a. Missing data estimation by the analogues method (thin line) and comparison with the original series (thick line). (a) Larch series; (b) Pine series. Original series are detrended using the Adaptative Regional Growth Curve (ARGC) method. All series are smoothed with a 20-year lowpass filter. Dark-grey shading denotes a period of increasing growth, light-grey shading reveals period of growth reduction. 


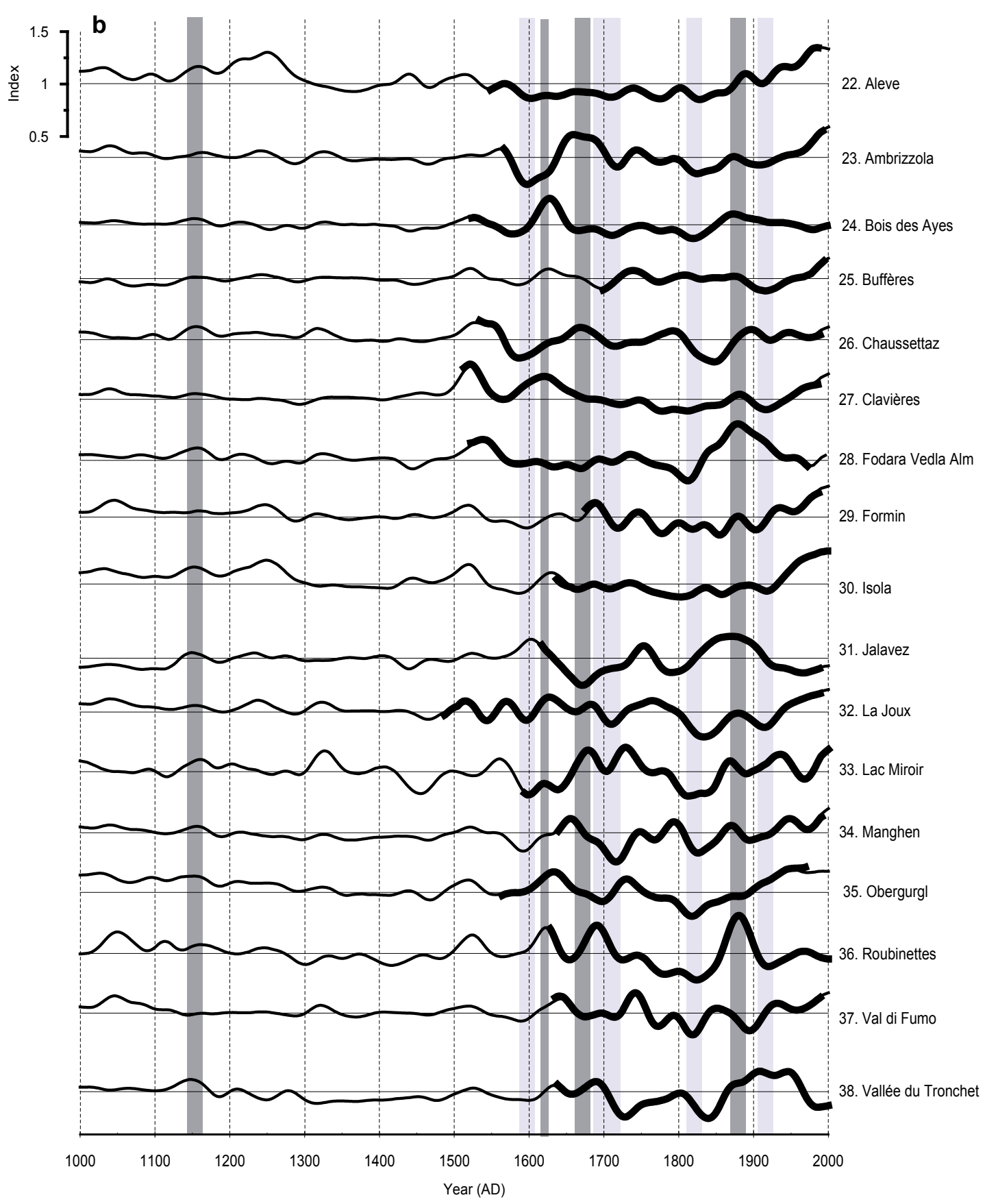

Fig. 2b. Continued.

to one. If this statistic is greater than zero, the reconstruction has greater skill than would be obtained by simply using the mean of the calibration period as the value for each year of the reconstruction (Fritts, 1976). The CE compares estimates with the mean of the verification period. It provides the more rigorous verification test, particularly when there are low-frequency variations and substantial differences in the means of the calibration and verification periods. The confidence interval for all these statistics are obtained from the 5th and 95th percentiles of the 50 reconstructions. Bootstrap technique then provides a way to decide statistically if the reconstruction is robust or not. 
Table 3. Estimation of the missing data by analogue method. The first column represents the percentage of missing values considering the period AD 1000-2000 as 100\%. The statistics are calculated between observed values and estimates, when they are available. All correlation coefficients are significant (at the $5 \%$ level).

\begin{tabular}{llllll}
\hline No. & Serie & $\begin{array}{l}\text { \% of } \\
\text { missing values }\end{array}$ & $\begin{array}{l}\text { Correlation } \\
(\mathrm{R})\end{array}$ & $\begin{array}{l}\text { Number of } \\
\text { observations }\end{array}$ & $\begin{array}{l}\text { correction factor } \\
\text { (ratio of std. dev) }\end{array}$ \\
\hline 1 & Aleve & 49.3 & 0.87 & 507 & 1.39 \\
2 & Alpe Musella & 57 & 0.89 & 430 & 1.09 \\
3 & Berchtesgaden & 47.2 & 0.91 & 528 & 1.57 \\
4 & Cadini Lago di Misurina & 57.5 & 0.89 & 425 & 1.41 \\
5 & Chalets de l'Orgère & 56.5 & 0.91 & 436 & 1.35 \\
6 & Chardonnet & 55 & 0.91 & 450 & 1.44 \\
7 & Clapouse & 62.6 & 0.88 & 374 & 1.38 \\
8 & Comasine & 46.3 & 0.91 & 537 & 1.36 \\
9 & Fodara Vedla Alm & 55.6 & 0.91 & 444 & 1.37 \\
10 & Freyssinières & 56.3 & 0.88 & 437 & 1.52 \\
11 & Merveilles & 2.6 & 0.98 & 974 & - \\
12 & Moutieres & 48.6 & 0.89 & 514 & 1.45 \\
13 & Muestair & 61.6 & 0.89 & 384 & 1.69 \\
14 & Névache Granges & 15.8 & 0.99 & 842 & 1 \\
15 & Obergurgl & 36.7 & 0.89 & 633 & 1.72 \\
16 & Oriol & 41.8 & 0.93 & 582 & 1.55 \\
17 & Passo Cinque Croci & 46.8 & 0.81 & 532 & 1.46 \\
18 & Ravin de Congerman & 62.4 & 0.84 & 376 & 1.56 \\
19 & Ventina & 31 & 0.97 & 690 & 1.26 \\
20 & Swiss1 (TRW) & 0 & 0.91 & 1001 & - \\
\hline
\end{tabular}

\section{Results}

\subsection{Chronology characteristics}

Common variance between the population series is likely dominated by species differences. The average interspecies cross-chronology correlation, calculated over the 1637-1974 common period, is 0.19 , lower than the intra-species mean correlations for larch $(R=0.38)$ or pine $(R=0.31)$. It seems also influenced by the distance between sampling sites. For Larix decidua, the lowest correlation $(R=-0.03)$ occurs between farther sites of Merveilles and Berchtesgaden while the highest $(R=0.72)$ is found between neighbour sites of Chardonnet and Chalets de l'Orgère (Fig. 1, Table 2). More generally, high correlations values $(R>0.6)$ are found between larch chronologies from Briançonnais, Chardonnet, Névache Granges, Oriol, Clapouse, and Chalets de l'Orgère, reflecting their proximity (Fig. 1, Table 2). Sim- ilarly, for Pinus cembra, highest correlations are found in Italian Dolomites between chronologies from Ambrizzola, Formin, Manghen and Val di Fumo.

The proxy matrix has 38 columns (chronologies) and 1001 rows (years) with many gaps, especially before 1500 . The percentage of missing values, considering the reconstruction (AD 1000-2000) as 100\%, is provided in Table 3. It varies between 0 and $68 \%$ with a mean of $49 \%$. Eight chronologies are available before AD 1400 and only 5 before AD 1200 (Fig. 3a, f). The analogue method provides us a good estimate of most of the gaps, as verified by comparing the true values, when available, with the estimates. Table 3 shows that correlation between observations and estimates varies from 0.83 to 0.99 with a mean of 0.90 . The correction factor applied to estimates in order to preserve the observed variance, varies from 1 (no correction) to 1.72 for Obergurgl larch chronology. The correlations computed for 100-year 
Table 3. Continued.

\begin{tabular}{|c|c|c|c|c|c|}
\hline No. & Serie & $\begin{array}{l}\% \text { of } \\
\text { missing values }\end{array}$ & $\begin{array}{l}\text { Correlation } \\
\text { (R) }\end{array}$ & $\begin{array}{l}\text { Number of } \\
\text { observations }\end{array}$ & $\begin{array}{l}\text { correction factor } \\
\text { (ratio of std. dev) }\end{array}$ \\
\hline 21 & Swiss2 (MXD) & 0 & 0.99 & 1001 & - \\
\hline 22 & Aleve & 53.9 & 0.86 & 461 & 1.48 \\
\hline 23 & Ambrizzola & 56 & 0.92 & 440 & 1.37 \\
\hline 24 & Bois des Ayes & 51.6 & 0.88 & 484 & 1.47 \\
\hline 25 & Buffères & 68 & 0.83 & 313 & 1.53 \\
\hline 26 & Chaussettaz & 53.2 & 0.87 & 468 & 1.59 \\
\hline 27 & Clavieres & 51.2 & 0.90 & 488 & 1.38 \\
\hline 28 & Fodara Vedla Alm & 51.2 & 0.90 & 488 & 1.46 \\
\hline 29 & Formin & 68 & 0.87 & 320 & 1.36 \\
\hline 30 & Isola & 66.5 & 0.86 & 335 & 1.36 \\
\hline 31 & Jalavez & 60.1 & 0.87 & 399 & 1.54 \\
\hline 32 & La Joux & 51.6 & 0.87 & 484 & 1.42 \\
\hline 33 & Lac Mirroir & 59.2 & 0.84 & 408 & 1.46 \\
\hline 34 & Manghen & 63.7 & 0.91 & 363 & 1.35 \\
\hline 35 & Obergurgl & 58.4 & 0.87 & 416 & 1.43 \\
\hline 36 & Roubinettes & 61.6 & 0.85 & 384 & 1.52 \\
\hline 37 & Val di Fumo & 63.8 & 0.87 & 362 & 1.40 \\
\hline \multirow[t]{2}{*}{38} & Vallee du Tronchet & 62.8 & 0.88 & 372 & 1.41 \\
\hline & Mean & 49 & 0.90 & & \\
\hline
\end{tabular}

segments in the original and in the infilled matrix are close (Fig. 3d, h). Interestingly, for larch chronologies (Fig. 3d), the intra-species correlations before 1200 , between 0.38 and 0.55 , reveal a fairly robust signal in the four oldest populations from Switzerland/Austria (Swiss 1, Swiss 2) and France (Merveilles, Nevache). Despite the distance and the composite nature of these populations, these correlations reveal a common climate-related signal in the Alps during the early part of the millennium for which regional temperature reconstructions considerably differ at regional scale (Mann, 2007). For the infilled series, mean correlation between 1050 and 1250 is 0.43 . It decreases to 0.23 (at the same order of magnitude than for the observed data) between 1400 and 1600 . For pine chronologies, correlations range between 0.14 and 0.45 with a minimum between 1500 and 1700 (Fig. 3h). The periods of decreasing correlation match with the beginning of the majority of the larch (pine) chronologies (Fig. 2). These populations are composed of juvenile trees that are less sensitive, especially for Larix decidua (Carrer and Urbinati 2004) to a lesser extent for Pinus cembra (Carrer and Urbinati, 2004) to climate. This climate signal age effect (Esper et al., 2008) might explain the low correlation. It appears to be related to an endogeneous parameter linked to hydraulic status that becomes increasingly limiting as tree grow and age, inducing more stressful conditions and a higher climate sensitivity in older individuals (Carrer and Urbinati, 2004).

The ARGC detrended larch and pine chronologies reveal inter-decadal scale growth variations over the past millennium. Visually, the original and infilled smoothed chronologies (Fig. 3a, b, d, e) show periods of similar inter-decadal fluctuations, with low values at $\sim 1585-1605$ and $\sim 1960$ 1980 , and high values at $\sim 1610-1620$, and $\sim 1860-1880$, and during the last decades. Interestingly, after 1620, the two chronologies are out of phase, with Pinus lagging behind Larix by 20 years. For example, during the Late Maunder Minimum 1675-1715, all larch chronologies show a prominent, multi-decadal growth reduction during the $\sim 1680$ 1700 period, whereas pine chronologies indicate a later and less important reduction at $\sim 1710-1720$. Between 1810 and 1821, almost all chronologies indicate reduced growth rates and by the end of the 19th century, the chronologies are back in phase. 
Table 4. Statistics of reconstructions of June to August temperature in the Alps functions of the number (10-18) of principal components used. Four neurons and a maximum of 5000 iterations were used in each reconstruction. Calibration statistics are computed on the randomly selected observations within the 1818-2003 period. Validation statistics are based on not taken observation within the same period. The RMSE and the $R^{2}$ statistic tests the quality of fit on the calibration data, while the RMSEP, RE and CE test the prediction capacity of the transfer function by using independent data.

\begin{tabular}{|c|c|c|c|c|c|c|c|c|c|}
\hline $\begin{array}{l}\text { Number of } \\
\text { principal components }\end{array}$ & 10 & 11 & 12 & 13 & 14 & 15 & 16 & 17 & 18 \\
\hline$\%$ of variance & 0.81 & 0.83 & 0.85 & 0.86 & 0.88 & 0.89 & 0.90 & 0.91 & 0.92 \\
\hline \multirow[t]{2}{*}{ RMSE } & 0.67 & 0.64 & 0.64 & 0.64 & 0.62 & 0.59 & 0.59 & 0.60 & 0.59 \\
\hline & {$[0.61 ; 0.71]$} & {$[0.59 ; 0.69]$} & {$[0.59 ; 0.70]$} & {$[0.57 ; 0.69]$} & {$[0.55 ; 0.69]$} & {$[0.54 ; 0.65]$} & {$[0.54 ; 0.66]$} & {$[0.56 ; 0.64]$} & {$[0.54 ; 0.64]$} \\
\hline \multirow[t]{2}{*}{ RMSEP } & 0.73 & 0.72 & 0.71 & 0.71 & 0.70 & 0.71 & 0.69 & 0.69 & 0.69 \\
\hline & {$[0.63 ; 0.83]$} & {$[0.63 ; 0.84]$} & {$[0.61 ; 0.82]$} & {$[0.62 ; 0.82]$} & {$[0.59 ; 0.81]$} & {$[0.61 ; 0.80]$} & {$[0.59 ; 0.78]$} & {$[0.59 ; 0.76]$} & {$[0.61 ; 0.80]$} \\
\hline \multirow[t]{2}{*}{$R^{2}$ (calibration) } & 0.43 & 0.46 & 0.47 & 0.49 & 0.51 & 0.55 & 0.54 & 0.55 & 0.55 \\
\hline & {$[0.32 ; 0.53]$} & {$[0.36 ; 0.56]$} & {$[0.34 ; 0.56]$} & {$[0.37 ; 0.59]$} & {$[0.40 ; 0.61]$} & {$[0.45 ; 0.66]$} & {$[0.45 ; 0.64]$} & {$[0.46 ; 0.64]$} & {$[0.43 ; 0.65]$} \\
\hline \multirow{2}{*}{$\begin{array}{l}\text { Reduction of } \\
\text { error (RE) }\end{array}$} & 0.32 & 0.34 & 0.37 & 0.35 & 0.39 & 0.38 & 0.38 & 0.38 & 0.38 \\
\hline & {$[0.14 ; 0.45]$} & {$[0.17 ; 0.46]$} & {$[0.21 ; 0.46]$} & {$[0.18 ; 0.48]$} & {$[0.19 ; 0.50]$} & {$[0.18 ; 0.51]$} & {$[0.22 ; 0.49]$} & {$[0.24 ; 0.48]$} & {$[0.21 ; 0.49]$} \\
\hline \multirow{2}{*}{$\begin{array}{l}\text { Coefficient of } \\
\text { efficiency (CE) }\end{array}$} & 0.31 & 0.33 & 0.35 & 0.32 & 0.37 & 0.37 & 0.37 & 0.37 & 0.37 \\
\hline & {$[0.12 ; 0.43]$} & {$[0.15 ; 0.46]$} & {$[0.17 ; 0.45]$} & {$[0.15 ; 0.47]$} & {$[0.19 ; 0.49]$} & {$[0.15 ; 0.46]$} & {$[0.17 ; 0.49]$} & {$[0.22 ; 0.48]$} & {$[0.13 ; 0.50]$} \\
\hline
\end{tabular}

\subsection{Calibration and validation}

The ANN was used with 4 neurons in the hidden layer, a maximum of 5000 iterations. The calibration is based on the randomly selected observations within the 1818-2003 period and the verification is done on the non taken observations. We have successively tested the inclusion of 10 to 19 principal components of the regressors, explaining from 81 to $92 \%$ of their variance. The optimal configuration seems to be 14 principal components explaining $88 \%$ of the regressor's variance and $51 \%$ of the predictand's variance $\left(R^{2}\right)$ with a $95 \%$ confidence interval of $[40 \%, 60 \%]$. It is considered as the optimum configuration because it gives the best verification statistics, say $\mathrm{RE}=0.39$ and $\mathrm{CE}=0.37$. These values, based on observations which were not taken into account within the 1818-2003 period, are largely significant with $95 \%$ confidence intervals of respectively [0.19, 0.50] and [0.19, 0.49]. The mean discrepancy between reconstructed and instrumental temperatures is $-0.07^{\circ} \mathrm{C}$ (Fig. 4a) for the $1818-2000$ period. Discrepancies are maximal at $1823\left(+2{ }^{\circ} \mathrm{C}\right)$ and 1976 $\left(-1.45^{\circ} \mathrm{C}\right)$ (Fig. 4a). When the curves are smoothed with a 20-year low-pass filter (Fig. 4b), we see a maximum decoupling between colder periods e.g. 1950-1970 $\left(-0.6^{\circ} \mathrm{C}\right)$, 1819-1825 $\left(-0.4^{\circ} \mathrm{C}\right)$ and $1875-1900\left(-0.25^{\circ} \mathrm{C}\right)($ Fig. $4 b)$.

An extra verification of the results is provided by the comparison between low-elevation instrumental data and our reconstruction on the 1760-1818 independent period (Fig. 4c): we obtained a $R^{2}$ of 0.40 , which is highly significant ( $p<$ 0.001 ) and comparable to the $\mathrm{CE}$ of 0.37 obtained on in- dependent observation randomly selected between 1819 and 2000. The tree-ring-based reconstruction of 1760-1818 temperature variability indicates discrepancies between "cooler" proxy and "warmer" instrumental prior to 1840 , similarly to Büntgen et al. (2005, 2006a) and Frank et al. (2007a). The reconstruction substantially underestimates temperatures during all the overlap period with early instrumental data with a maximal gap in $1832\left(-2.3^{\circ} \mathrm{C}\right.$, Fig. $\left.4 \mathrm{c}\right)$ and a mean divergence $(1760-1818)$ of $-0.75^{\circ} \mathrm{C}$. For the 20 -yr low pass curves, $R^{2}$ is 0.45 before 1819 and increases to 0.81 between 1819 and 2000 (Fig. 4d). This statement proves that the reconstruction is slightly better in the low frequency domain than in the high frequency one.

\section{Discussion}

The discussion is lead by considering first methodological points and then by analysing the Alpine climate and by comparing the reconstructed climatic variations at different geographical scales (region, hemisphere).

\subsection{Comparison of the reconstruction to the proxies}

Several hypotheses concerning proxy and target have been invoked to explain this observed systematic tree-ring underestimates of early instrumental temperature: (1) tree-ring detrending, (2) biological persistence, (3) non linearity in the climate/growth relationships and (4) instrumental data availability (Frank et al., 2007a). 


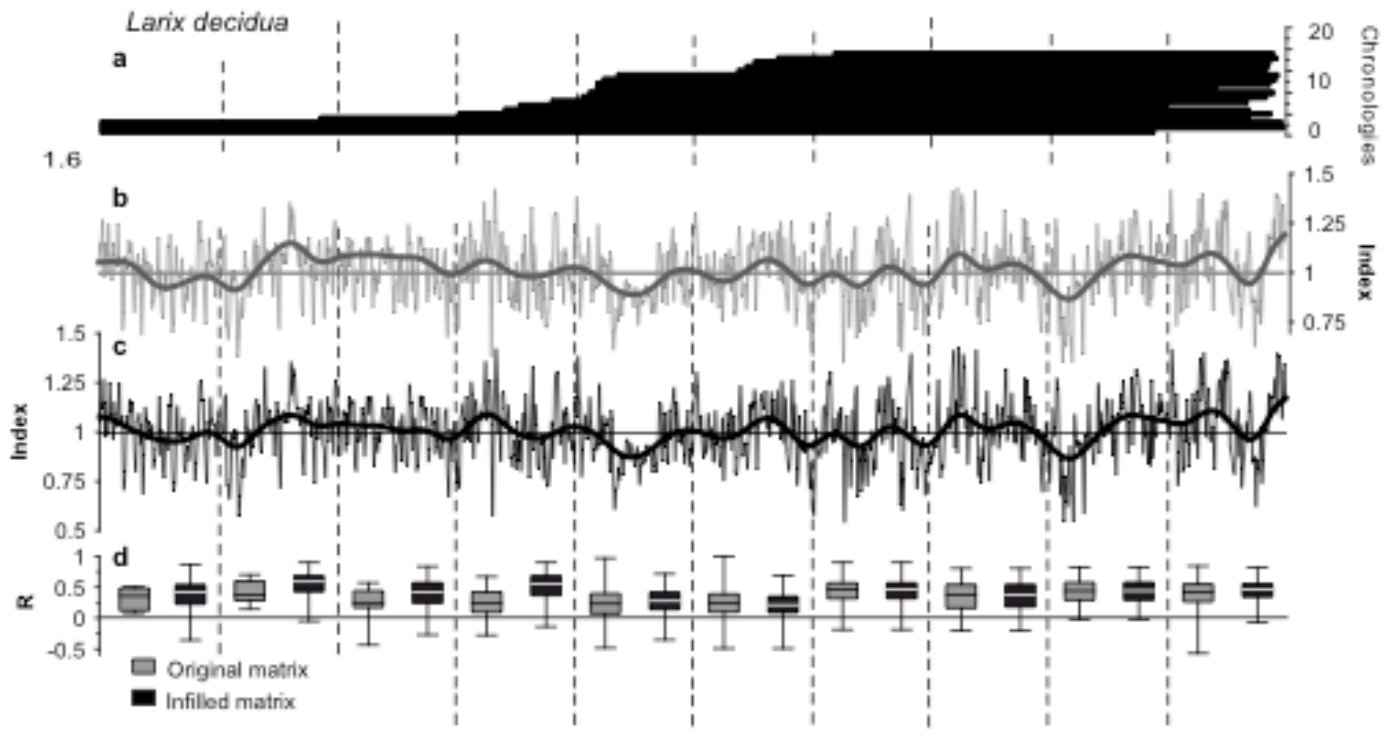

Pinus cembra

e
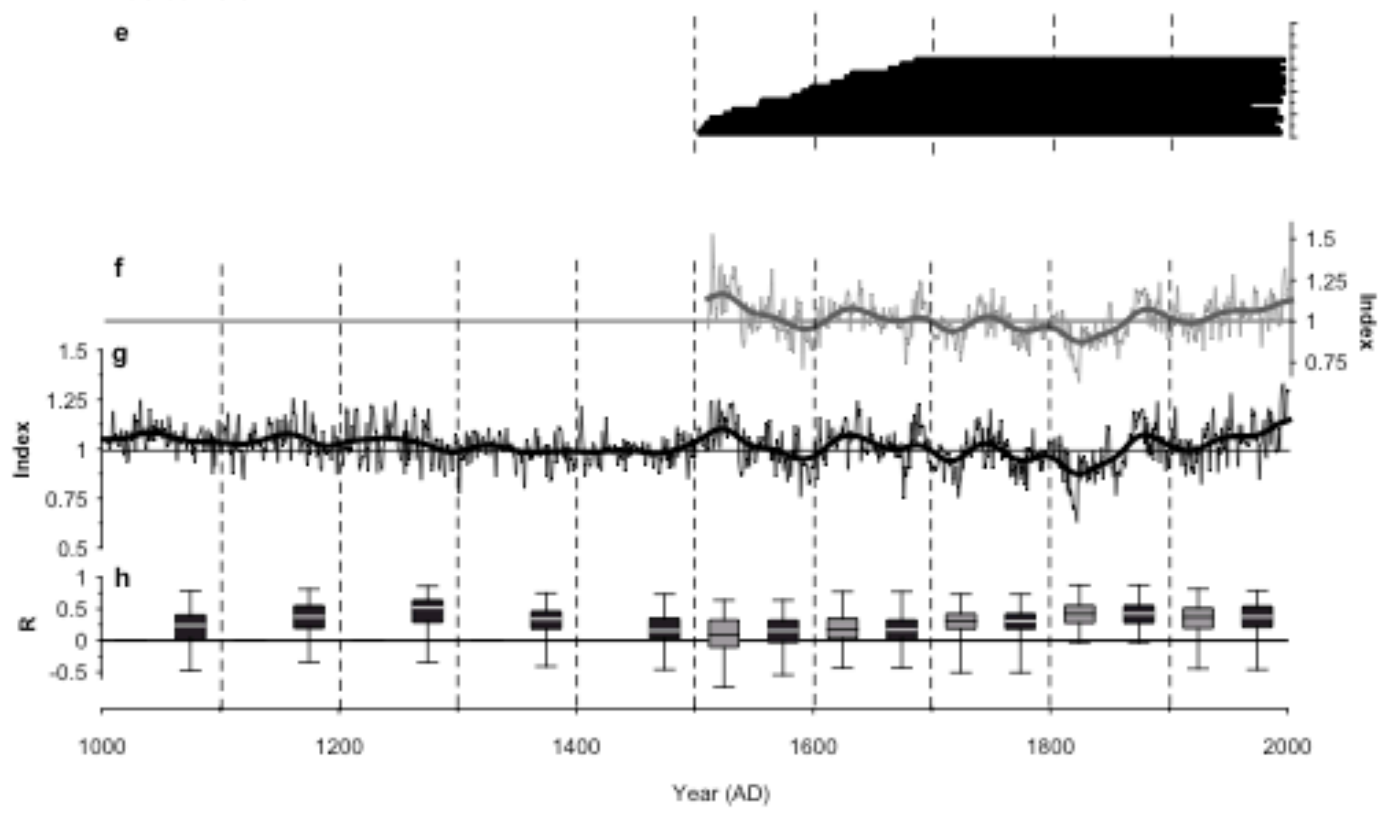

Fig. 3. Adaptative Regional Growth Curve (ARGC) detrended alpine chronologies and signal robustness. (a), (e), distribution of the chronologies with each bar representing a single chronology. The alpine larch (b), (c) and pine (f), (g) ARGC detrended chronologies are calculated for original (b, f, grey) and infilled (c, g, black) matrixes. The thick lines derive from 20-years low-pass filtering. The box-plots (d), (h) display the mean correlations computed for 100-years segments in each matrix.

About the detrending methods, several reconstructions of summer temperatures using independent datasets and both individual spline fits and RCS techniques (Büntgen et al., 2005, 2006a; Casty et al., 2005; Frank and Esper, 2005) similarly underestimated the early instrumental data. This discrepancy also appears in this study even with the new detrending ARGC technique. It is then not likely that these systematic discrepancies can be explained by standardisation.
The divergence due to biological persistence is demonstrated to be maximal in alpine TRW reconstructions during the temperature minima around 1815 (Frank et al., 2007a). During this cold period, the tree growth reduction endured during several consecutive years likely because of detriments in mobilizing resources from root and needle following stressful years (Frank et al., 2007a), leading to an underestimation of the temperatures. This bias is absent in our reconstruction (Fig. 4c) like in other TRW-MXD (Büntgen 


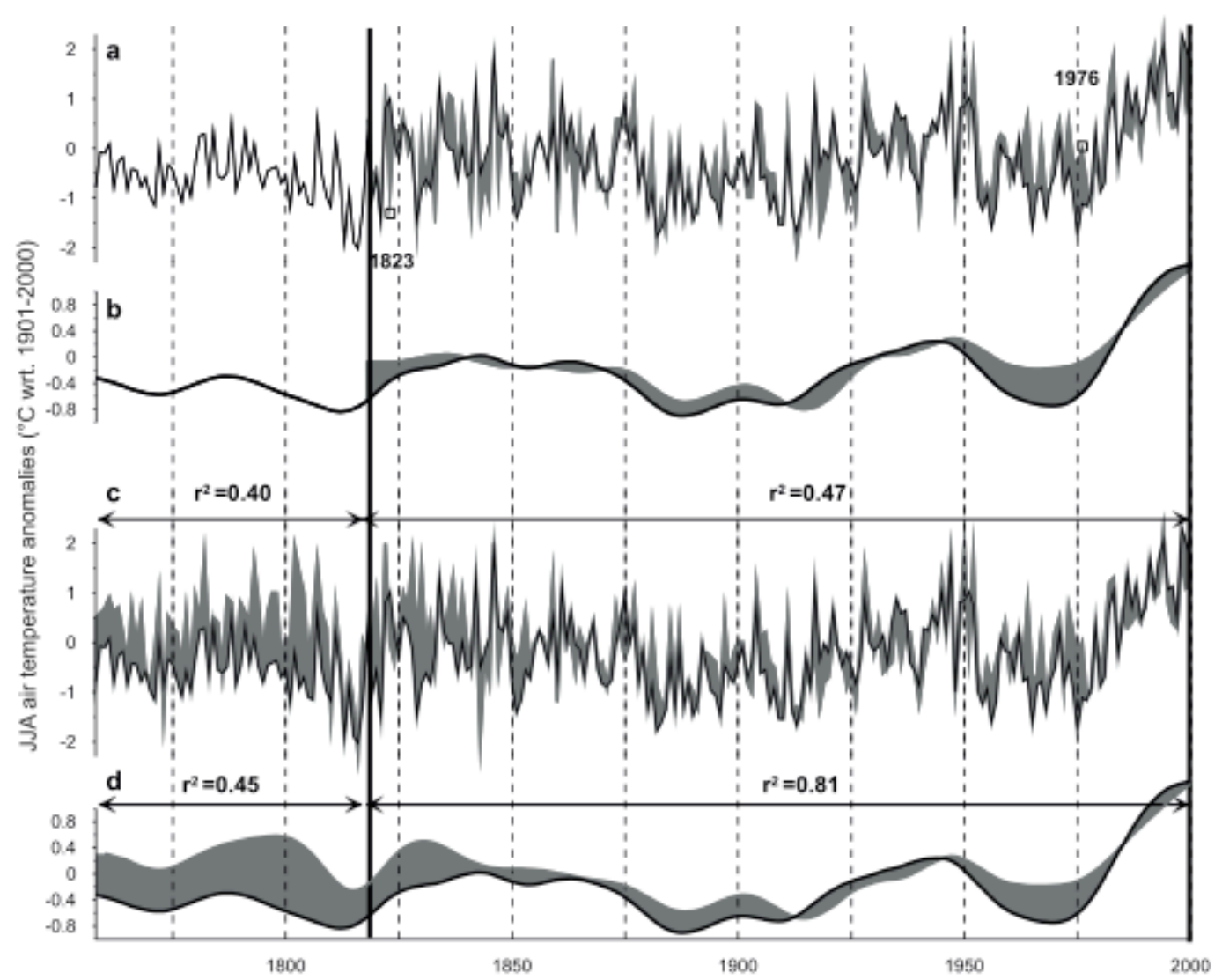

Fig. 4. Comparison of the bootstrap ANN reconstruction of the JJA temperatures against the high-elevation (a, grey) JJA mean temperatures (1818-2000) and extra verification using low-elevation data (c, grey) back to 1760. (b), (d): the 20-year low-pass filter of the bootstrap ANN reconstruction (black) and JJA mean temperatures at high and low elevations (grey). Temperatures are expressed as anomalies with regard to 1901-2000. Grey shadings denote the offset between (warmer) early instrumental and (colder) proxy data.

et al., 2006a) or MXD (Frank and Esper, 2005) reconstructions thanks to the lower autocorrelation existing in MXD data (Cook and Kairiukstis, 1990). This phenomenon seems then to have the largest consequences on the early wood.

Concerning the climate/tree-growth relationships, we know that a large variety of environmental variables are integrated by tree growth. Moreover, trees can carry more of an annual signal in the lower frequency domain due to physiological processes and feedbacks (for example, photosynthesis occurring outside the growing season) (Frank and Esper, 2005). Thus, the selection of only one instrumental parameter as a reconstruction target may be responsible for uncertainties in proxy/target relationships. Moreover, the relative influence of environmental factors may shift over time as shown in some studies demonstrating change in the sensitivity of hemispheric tree-growth to temperature forcing and possible response shifts between temperatures and precipitation (Briffa et al., 1998).

The reduction of instrumental data coverage back in time (in the GAR, 36 temperatures series go back to 1850,16 extend prior to 1800), particularly at higher elevations, increases the weight of single stations in explaining the surrounding climatic variations (Frank et al., 2007a). This makes also difficult the homogenization of instrumental data. The decoupling of target and proxy data is maximal before 1818. It coincides with the use of the HISTALP lowelevation temperature time series doubtlessly highly correlated to the high-elevation time series but also less replicated, with more data gaps, a large amount of inhomogeneities and generally recorded by urban stations (Büntgen et al., 2006a). This decline in data quality and the elevational differences between tree ring sites and meteorological stations might explain a large part of the observed discrepancy (see Frank et al., 2007a for further discussion).

Some additional discussion can be done on the calibration method. The ANN method is not linear and works as a black box. It does not give any indication such as which of the predictors most influence the reconstruction (Guiot et al., 2005). Even if $\mathrm{Ni}$ et al. (2002) conclude that it is an intrinsic advantage of the ANN method to focus on the net effect of all the 


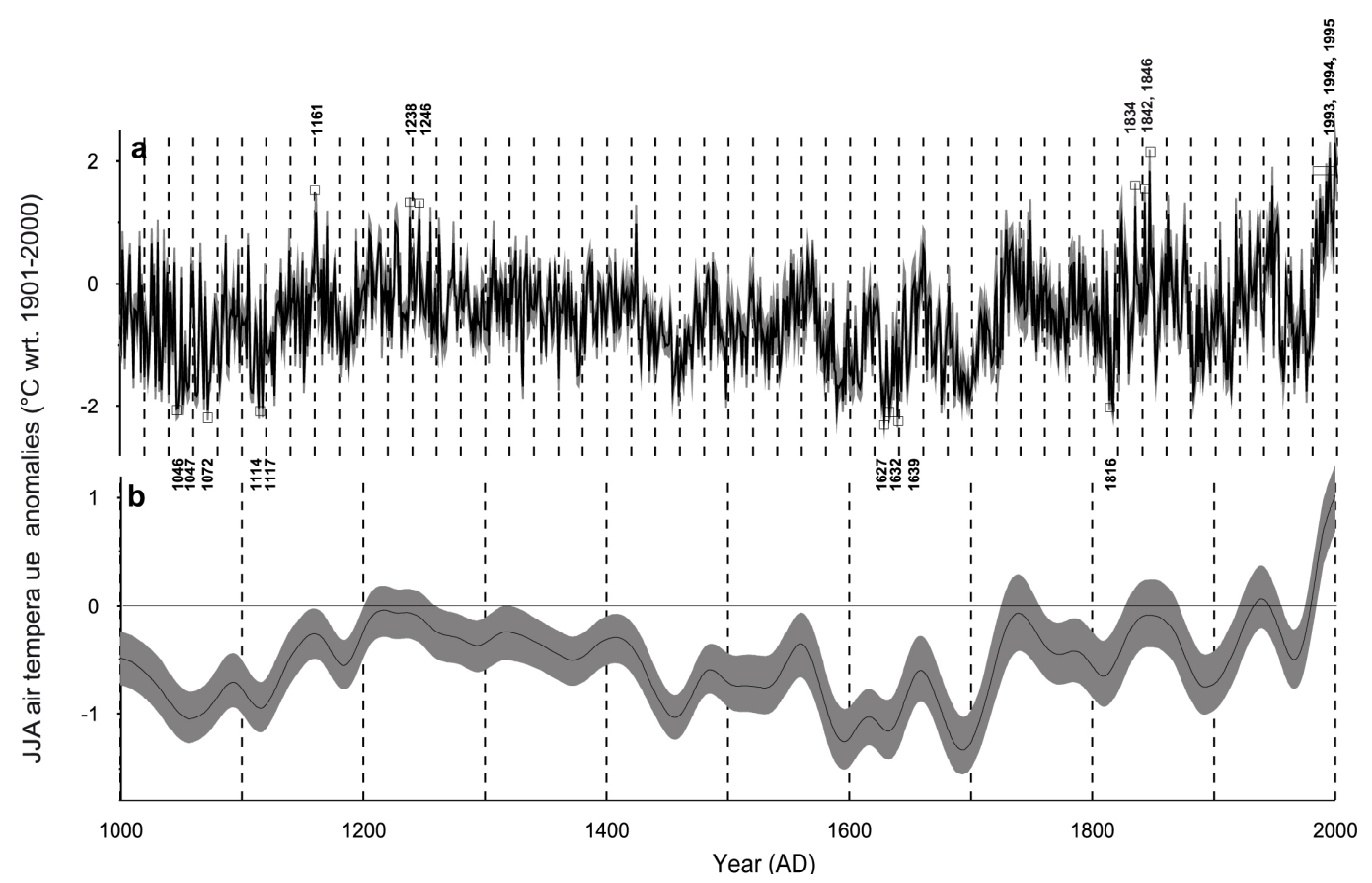

Fig. 5. Alpine summer temperatures reconstruction (a) with the white boxes denoting the warmest and coldest years, and the smoothed black line (b) being a 20-year low pass filter with $95 \%$ bootstrap confidence limits (gray). Temperatures are expressed as anomalies with respect to $1901-2000$.

predictors (including the numerous interactions) rather than on each predictor as in a linear regression, it may be instructive to calculate the correlation between each predictor and the reconstructed series. Table 5 shows the significantly (at the $p=0.05$ level) correlated predictors ordered according to decreasing correlation. The first five chronologies are from eastern Alps, with a correlation ranging from 0.57 and 0.70 , and especially from Swiss Alps and Italian Dolomites. The proximity of these chronologies with the high temperatures time series used for calibration and centred on central Alps (Auer et al., 2007) may explain these high correlations.

\subsection{Alpine climate history}

We first present the raw reconstruction and we then characterise warm and cold years anomalies for the period AD 1000 and 1900, and for the 20th century.

\subsubsection{Raw reconstruction: high frequencies (year-to-year) variations}

Figure 5a shows the raw summer reconstruction.

\section{Warm years anomalies (AD 1000-1900)}

Before 1986, summer anomalies compared to 1901-2000 exceeded two standard deviations $\left(+1.2^{\circ} \mathrm{C}\right)$ in $1834\left(+1.3^{\circ} \mathrm{C}\right)$, $1842\left(+1.3^{\circ} \mathrm{C}\right)$ and $1846\left(+1.9^{\circ} \mathrm{C}\right)$. These three years coincides with early grape harvests beginning before 18 th
September in Burgundy (Chuine et al., 2004). In the beginning of the reconstruction period, years 1161,1238 and 1246 were also among the warmest $\left(+1.2^{\circ} \mathrm{C},+1.1^{\circ} \mathrm{C}\right.$, and $+1.1^{\circ} \mathrm{C}$ respectively). The two latest are reported, in northern Europe, amongst the hottest of the 13th century (Jones et al., 2001).

\section{Cold years anomalies (AD 1000-1900)}

The first relatively cold period can be found between 1040 and 1140 with particularly cold summers in $1072\left(-2.1^{\circ} \mathrm{C}\right)$, $1114,1117,1046$ and $1047\left(-2{ }^{\circ} \mathrm{C}\right)$. These years belong to a period (1088-1137) characterised by a short advance of the Grindelwald Glacier (Swiss Alps) in a larger context of durable retreat during the Medieval Period (Holzhauser et al., 2005). Summers of 1639, 1627 and 1632 were the three coldest summers during the last millennium with respective anomalies of $-2.2^{\circ} \mathrm{C}$ and $-2.1^{\circ} \mathrm{C}$ and $-2.2^{\circ} \mathrm{C}$. They were shown to be also cold in Ile de France (Etien et al., 2008). Extreme cold conditions characterized the year 1627 until the beginning of July for Central Europe, as deciphered from historical sources (Pfister, 1999), and also denoted by snowfall as late as June (Casty et al., 2005). For 1632, late grape harvest dates were reported in Burgundy (Chuine et al., 2004). The summer of 1639 reconstructed from harvest dates appears rather mild in Burgundy (Chuine et al., 2004), while in central Europe, historical sources describe a rather cold summer (Pfister, 1999). Year 1816 is recorded as the absolute 


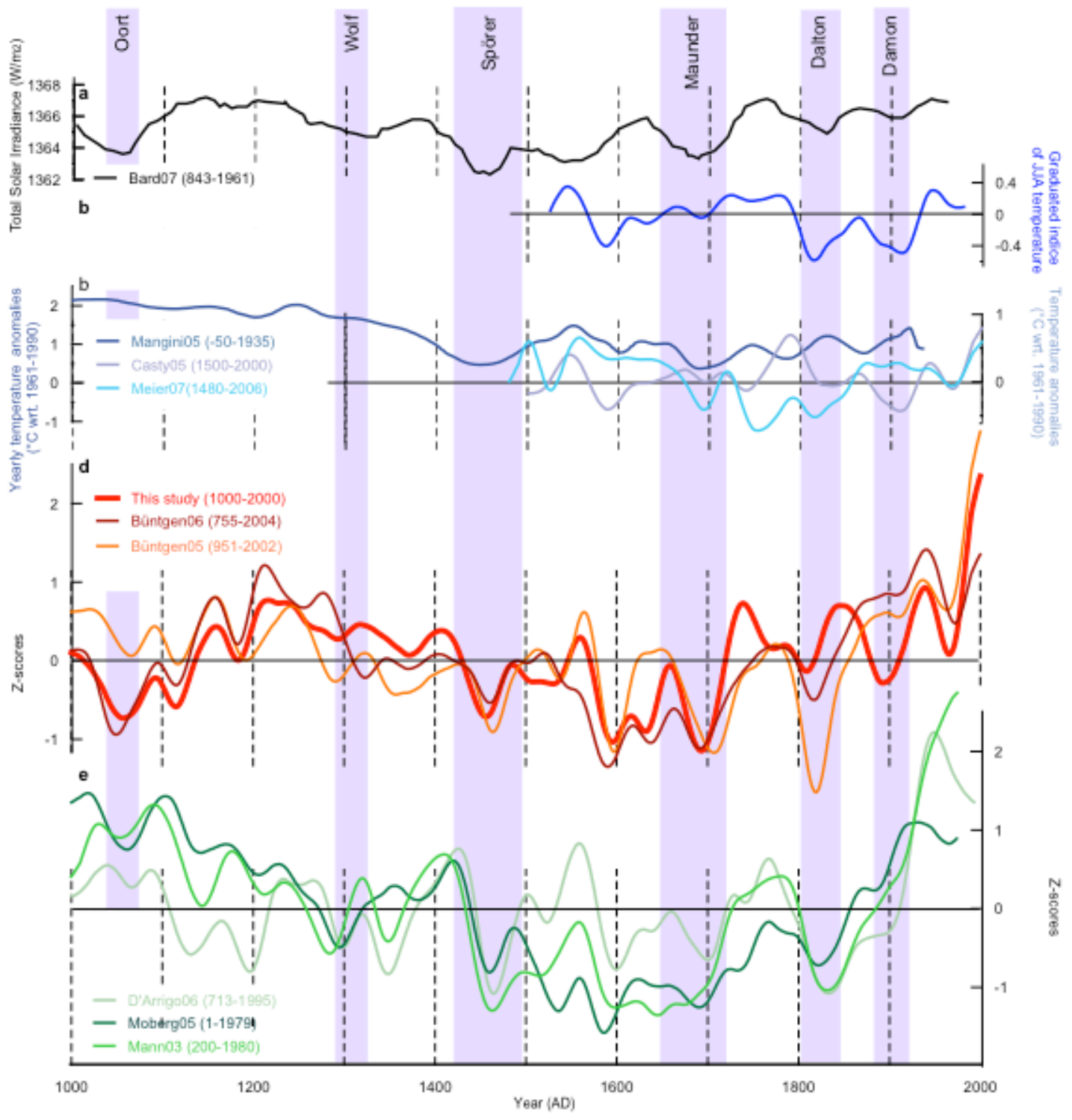

Fig. 6. Comparison of regional and large-scale temperature reconstructions. All reconstructions were 20-yr low-pass filtered. (a) The solar irradiance variations (black) reconstructed by Bard et al. (2007). Shadings denote the timing of great solar minima. (b) The average value of June to August graduated indices of Pfister et al. (1994). (c) The speleothem yearly temperature reconstruction (dark blue) of Mangini et al. (2005), the grape harvest April-August temperature reconstruction of Meier et al. (2007) and the multi-proxy JJA temperature reconstruction (light blue) of Casty et al. (2005); the original record was adjusted to have the same mean as our reconstruction during the 1901-2000 period. (d) Our reconstruction (red; this study), the MXD-based Alpine temperature reconstruction (brown; Büntgen et al., 2006) and RW-based reconstruction (orange; Büntgen et al., 2005). (e) Large-scale temperature reconstructions representing the Northern Hemisphere (green, Mann and Jones, 2003, multi-proxy; dark green, Moberg et al., 2005, multi-proxy; light green, D'arrigo et al., 2006, treerings). All temperature reconstructions were transformed to z scores over the 1000-1979 common period.

coldest Alpine summer by Pfister $(1992,1999)$ and Casty et al. (2005), becoming known in the New World as "the year without summer" (Harrington, 1992; Robock, 1994). In our reconstruction, this year appears, at least in summer, of the same order of magnitude or even slighty lower, than several years discussed above $\left(-2^{\circ} \mathrm{C}\right)$.

\section{The 20th century}

After 1986, our reconstruction exceeded nine times (1986, $1988,1991,1993,1994,1998,1999,2000)$ the threshold of $1.2^{\circ} \mathrm{C}$. This succession of positive extremes during the last 15 years is remarkable. In the Alpine area, 1994, 1995 and 1993 were the warmest summers of the instrumental period, 
Table 5. Correlation coefficient between the reconstructed temperature of Alps and the proxies used (after estimating the missing data with the analogue method). Coefficients are calculated on the total length of the period analysis, i.e., 1001 observations. Species: LADE: Larix decidua; PICE: Pinus cembra. The horizontal line indicates significant correlation coefficients (at the 5\% level).

\begin{tabular}{llll}
\hline No. & Chronologies & Species & Correlation \\
\hline 21 & Swiss2 (MXD) & LADE & 0.70 \\
4 & Cadini Lago di Misurina & LADE & 0.57 \\
8 & Comasine & LADE & 0.57 \\
9 & Fodara Vedla Alm & LADE & 0.57 \\
20 & Swiss1 (TRW) & LADE, PICE & 0.57 \\
2 & Alpe Musella & LADE & 0.51 \\
25 & Buffères & PICE & 0.48 \\
19 & Ventina & LADE & 0.47 \\
5 & Chalets de l'Orgère & LADE & 0.46 \\
17 & Passo Cinque Croci & LADE & 0.45 \\
6 & Chardonnet & LADE & 0.44 \\
14 & Névache Granges & LADE & 0.43 \\
34 & Manghen & PICE & 0.41 \\
3 & Berchtesgaden & LADE & 0.40 \\
23 & Ambrizzola & PICE & 0.40 \\
13 & Muestair & LADE & 0.39 \\
22 & Aleve & LADE & 0.39 \\
1 & Aleve & LADE & 0.35 \\
\hline
\end{tabular}

with anomalies greater than $+2{ }^{\circ} \mathrm{C}$ compared with the summer mean temperature 1901-2000. The 95\%-level error bars calculated by adding the bootstrap error (related to the quality of the calibration sample) and the residual error (related to the quality of the model selected) is on average $0.57^{\circ} \mathrm{C}$.

\subsubsection{Smoothed reconstruction: low-frequencies climatic variations and possible related forcing}

\section{Overview}

Figure $5 \mathrm{~b}$ shows the smoothed summer reconstruction. We recontruct long cold periods from the second half of the 11 th and the first half of the 12 th century $\left(-0.5^{\circ} \mathrm{C}\right.$ below the 1901-2000 average) and between the late 16th century and the early 18 th century $\left(-0.8^{\circ} \mathrm{C}\right)$. The culmination is achieved between 1685 and $1705\left(-1.1^{\circ} \mathrm{C}\right)$, which appears to be the coldest decades of the millennium. By contrast, a warm period is reconstructed between 1200 and 1420 $\left(+0.4^{\circ} \mathrm{C}\right)$. The first decades of the 13th century $(1300-1340)$
Table 5. Continued.

\begin{tabular}{|c|c|c|c|}
\hline No. & Chronologies & Species & Correlation \\
\hline 12 & Moutieres & LADE & 0.33 \\
\hline 15 & Obergurgl & LADE & 0.32 \\
\hline 35 & Obergurgl & PICE & 0.29 \\
\hline 28 & Fodara Vedla Alm & PICE & 0.27 \\
\hline 32 & La Joux & PICE & 0.27 \\
\hline 7 & Clapouse & LADE & 0.26 \\
\hline 29 & Formin & PICE & 0.26 \\
\hline 30 & Isola & PICE & 0.26 \\
\hline 37 & Val di Fumo & PICE & 0.26 \\
\hline 26 & Chaussettaz & PICE & 0.24 \\
\hline 31 & Jalavez & PICE & 0.22 \\
\hline 24 & Bois des Ayes & PICE & 0.20 \\
\hline 16 & Oriol & LADE & 0.19 \\
\hline 10 & Freyssinières & LADE & 0.14 \\
\hline 18 & Ravin de Congerman & LADE & 0.12 \\
\hline 27 & Clavieres & PICE & 0.09 \\
\hline 11 & Merveilles & LADE & 0.06 \\
\hline 38 & Vallee du Tronchet & PICE & -0.13 \\
\hline 33 & Lac Miroir & PICE & -0.16 \\
\hline 36 & Roubinettes & PICE & -0.18 \\
\hline
\end{tabular}

are clearly the warmest of the millennium $\left(+0.7^{\circ} \mathrm{C}\right)$ until 1980-2000 $\left(+1.8^{\circ} \mathrm{C}\right)$. Warm summers were also recorded around 1550 and during the second half of 18 th century.

\section{Solar activity}

Correlations between the low-frequency solar activity and the 20 year-smoothed temperature reconstruction are 0.21 over their common period respectively. Even though, the correlation is not significant at $p<0.05$ level, records share high values (0.41) during the twelfth and thirteenth centuries (great solar maximum; Eddy, 1976) a prolonged depression during 1350-1600 (0.21) and an increasing values toward the twentieth century $(0.31)$. The prominent interdecadal solar minima, Oort, Wolf, Spörer, Maunder, Dalton, and Damon as well as the corresponding maxima are superimposed upon this secular trend. The relatively cold conditions during the mid-11th century to the mid-12th century with a minimum during the decade 1045-1055 can be related to the Oort solar depression (Bard et al., 2007, Fig. 6a) with magnitude comparable to that of the Late Maunder Minimum during 
1675-1715 (Shindell et al., 2001). Warmer conditions during the end of the 12th and the 13th centuries of the millennium are associated in Europe with the Medieval Warm Period (Hugues and Diaz, 1994) coinciding with the Medieval solar maximum (Eddy, 1976). It is characterized at high altitude, in the French Alps by its shortness and by significant interdecadal variations. Warmer decades are centered around 1160, 1240 and 1315. Summer temperatures steadily decrease from mid-14th century. Between 1400 and 1720, if we except decades centred on 1410 and 1560, the reconstruction indicates below-average temperatures, accompanied by significant inter-decadal variations. Key fluctuations are low temperatures in the 1460s, 1600s and around 1700. These coldest periods of the LIA coincide with the Spörer and Maunder solar minima (Fig. 6a). The cooling beginning in the mid-18th century is in phase with the decrease of the solar irradiance.

\section{Volcanic activity}

The pronounced cooling of summer temperatures, during the period 1805-1820, recorded in Alpine glacier advances (Holzhauser et al., 2005; Zumbühl et al., 2008), is characterized by a sequence of larger volcanic eruptions: in 1808, with unknown location (Dai et al., 1991), in 1813 in Awu, Soufriere, St. Vincent, Suwanose-Jima (Büntgen et al., 2006a) and in 1815 in Tambora/Indonesia (Sigurdsson and Carey, 1989; Crowley, 2000; Oppenheimer, 2003). Happening during the Dalton solar minimum, these eruptions most likely lead to an accumulated aerosol cooling effect (Esper et al., 2007).

\section{Anthropogenic activity}

During the industrial period, the proportion of man-made forcing agents on the earth's climate system increases comparatively to natural forcing agents (Anderson et al., 2003; Crowley 2000; Meehl et al., 2003). Since the end of the Late Maunder Minimum, temperatures discontinuously increased until the end of the record in 2000. This trend and the inter-decadal variations of the reconstructed temperatures seen since the beginning of the 19th century are in line with JJA instrumental temperatures recorded in the Alps (Auer et al., 2007). The global and northern hemispheric warming of the 20th century (e.g. Folland et al., 2001) and in Europe (e.g. Luterbacher et al., 2004) is also prominent at high altitude in the GAR (Casty et al. 2005; Büntgen et al., 2005, 2006a). It occurred in mainly two stages: between 1880 and 1945 and since 1975. If we consider the last three centuries (17002000), the warming is higher than $2.5^{\circ} \mathrm{C}\left(0.08^{\circ} \mathrm{C} /\right.$ decade $)$, but it is mainly due to two important steps, the first one likely linked with natural forcings (beginning of 18th century) and the second being anthopogenic (end of 20th century). Nevertheless, the anthopogenic step, compared to 1730-1980, remains as $1.3{ }^{\circ} \mathrm{C}$.

\subsection{Comparison with other reconstructions}

\subsubsection{Regional-scale comparisons}

To further assess the reconstructed Alpine JJA temperature history, we compare the new record with regional scale reconstructions by Pfister94 (Pfister et al., 1994), Meier07 (Meier et al., 2007), Mangini05 (Mangini et al., 2005), Casty05 (Casty et al., 2005), Büntgen05 (Büntgen et al., 2005) and Büntgen06 (Büntgen et al., 2006a). The Pfister94 graduated indices of summer temperatures (15251990) covers central Europe and are related to biological indicators such as dendro-climatic data, phenological observations, para-phenological indicators such as grape or vine harvest dates. Monthly Graduated Indexes GI, range from -3 to +3 (from very cold to very warm anomalies), 0 being "average" months or data not available (according to the 1901-1960 period). On a seasonal level the GI is defined as the average of the monthly GI, which yields gradations of 0.3 between -3 and +3 . The Meier07 April-August reconstruction concerns specifically Switzerland. It is derived back to 1480 from an annually resolved record of grape harvest dates calibrated with monthly data from the Basel and Geneva stations (1928-1979) and verified over 1980-2006. The Mangini05 summer reconstruction is based on the precisely dated isotopic composition of a stalagmite from Spannagel Cave (2524 m a.s.l.) in the Central Alps of Austria. The reconstruction covers the last millennium with a mean temporal resolution of three years. Despite it concerns the whole year, this reconstruction is used for comparison because it is fully independent from our dataset. The Casty05 grid$\operatorname{ded}\left(0.5^{\circ} \times 0.5^{\circ} \mathrm{lat} / \mathrm{long}\right)$ reconstruction covers the European Alpine region using long instrumental data in combination with documentary proxy evidence. Monthly (seasonal) grids are reconstructed back to 1659 (1500-1658). The data detailed by Mitchell et al. (2005) comprising monthly global land surface temperatures for the 1901-2000 period with $0.5^{\circ}$ resolution serve as predictands. Here, for purposes of comparison, a mean JJA series, representing the studied zone, is calculated from 56 homogeneous grid-points. The Büntgen05 reconstruction covers the Eastern Alps extends back to 951 . The dataset consists in 1527 subalpine larch and pine ring width series. For the calibration of proxy data, 11 high-elevation meteorological station records are used (Böhm et al., 2001). Finally, Büntgen06 is also centered on Swiss and Austrian Alps. It compiled 180 MXD larch series dating from 735-2004. The HISTALP high temperatures time series of the GAR spanning the 1818-2003 period are considered. Both reconstructions used the RCS method to standardize dendrochronological series. Our dataset integrates Swiss1 and Swiss2 chronologies used as regressors in Büntgen05 and Büntgen06 reconstructions, respectively. All data have been smoothed with a 20 year low-pass filter. 
According to the comparison provided in Fig. 6, the smoothed Pfister94 reconstruction (Fig. 6b) correlates at 0.48 (1525-2000) with our reconstruction, revealing similar interannual variations between indexes from historical documents and our reconstruction. On low and medium frequency, both signals show the same trends during cool periods in 1590 , 1810 and 1910 and warm periods in 1550, 1850 and 1940.

The Mangini05 record (Fig. 6c) correlates at 0.30 $(p<0.05)$ with our record. It reveals warm conditions during the putative Medieval Warm Period (1000-1300) early in the last millennium, followed by cooler conditions during the LIA e.g. around 1600,1700 and 1820 , partly similar to the trends displayed in our reconstruction. However, temperatures during the eleventh and twelfth centuries in Mangini05 are higher than in our study (Fig. 6c, d). The four oldest populations used in our study shared a strong common signal between 1000 and 1200 . Thus, this discrepancy can hardly be related to the decline of replication back in time. Moreover, cool summers around 1050 and 1120 are in phase with Oort solar minimum and with the advance of the Great Aletsch Glacier around 1100. Finally, the Mangini05 curve ends at about 1930, making difficult to evaluate the Medieval warm in the light of the 20th century. The filtered Meier07 record has lower amplitude than our reconstruction. The greater amplitude of our reconstruction can be related to both scaling uncertainties/dependence upon particular statistical reconstruction approaches as well as amplitude dependence upon both the spatial and temporal scales of interest (e.g., Esper et al., 2005). The courses of both curves are similar between 1660-1710, 1800-1830 and 1950-2000. A divergence of the curves is seen mainly between 1600-1660, 1730-1760 and 1880-1950. Such discrepancies may be explained by changing viticultural traditions (Lachiver, 1988), the varieties cultivated, the style of wine produced, the quality sought, the agricultural practices (García de Cortázar-Atauri et al., 2010) or other environmental influences than temperature. For example, anomalously high September precipitations fosters diseases and irregular sugar assimilation and, thus, distort the accuracy of the temperature signal recorded (Meier et al., 2007). These uncertainties on grape harvest dates and grape harvest-based reconstructions are discussed extensively and quantified by García de Cortázar-Atauri et al. (2010).

Casty05 is calibrated against different instrumental target records. Yet, the amplitude between the coldest and the warmest year over the past 500 years are close, i.e. $4^{\circ} \mathrm{C}$ (between 1807 and 1816) for Casty 05 and $4.5^{\circ} \mathrm{C}$ (between 1639 and 1998) here. The smoothed Casty05 correlates at $0.50(p<0.05)$ with our record over their 1500-2000 common period and similar courses are observed during the periods 1500-1620 and 1800-2000. A major discrepancy occurs around 1750. During this period, our reconstruction might be influenced by differences between larch and pine datasets (Fig. 3). Before 1800, Casty05 is systematically higher than our reconstruction but also displays increasing uncertainties related to inhomogeneities in the instrumental data before the mid-19th century as reported by Luterbacher et al. (2004). A bias as 0.7 to $0.8^{\circ} \mathrm{C}$ (Möberg et al., 2003) and up to $1-2^{\circ} \mathrm{C}$ (Etien et al., 2008) before 1860, could exist in temperatures, likely because of insufficient or inadequate shading apparatus of the thermometers, and may explain the differences between both reconstructions.

Unsurprisingly, our reconstruction, not fully independent of Büntgen05 and Büntgen06, shared a high common signal with both alpine reconstructions. Büntgen05 and Büntgen06 respectively correlate at $0.56(p<0.05)$ and $0.70(p<0.05)$ $(0.57(p<0.05)$ and $0.77(p<0.05)$ after smoothing $)$ with our record. The range of inter-annual variations of our curve is also quite similar to Büntgen 05 , i.e. $4.2^{\circ} \mathrm{C}$ (between 1821 and 2000) but slightly lower than Büntgen06 $\left(6.2^{\circ} \mathrm{C}\right.$, between 1816 and 1928). This difference may be due to enhanced interannual climate response of the MXD data (Büntgen06) considered as having a lower biological memory as compared to their RW counterparts (Frank et al., 2007). In details, between 1430 and 1700 our reconstruction remains in phase with Büntgen05 and Büntgen06, despite the introduction of several populations from the western Alps in the dataset, indicating a generalised cooling of the GAR during the LIA. Between1720 and 1920, our reconstruction slightly differs from Büntgen05 and Büntgen06. Higher temperatures are reconstructed at the end of the Maunder minimum (1720's) and the Dalton solar minimum (1820's) is less pronounced (Fig. 6d). They are related with growth increases in several of the most Western chronologies used for reconstruction, e.g. Chardonnet, Freyssinières, Névaches Granges or Lac Miroir and absents in eastern populations. These periods match with abnormal dry conditions in Europe (Pauling et al., 2006) and in the Alps (Casty et al., 2005) and a lower drought sensitivity of Western populations exposed to oceanic conditions might explain the observed differences. This hypothesis is consistent with recent studies showing the existence of longitudinal gradients of chronologies responses for coniferous species (Frank and Esper, 2005b; Carrer et al. 2007).

\subsubsection{Hemispheric-scale comparisons}

Comparisons are carried out with the hemispheric treering-based D'Arrigo06 (D'Arrigo et al., 2006), and the multiproxy-based Mann03 (Mann et al., 2003) and Moberg05 (Moberg et al., 2005) reconstructions (Fig. 6e). Alpine like other regional temperature changes have, as expected, larger amplitudes of variations than those averaged over large areas (e.g. Mann et al., 2000; Luterbacher et al., 2004; Jones and Mann, 2004; Brazdil et al., 2005; Xoplaki et al., 2005). Correlations between this study and Mann03, D'Arrigo06, and Moberg05, computed over the 1000-1979 common period are $0.18,0.18$ and 0.19 . They are 0.50 $(p<0.05), 0.30(p<0.05)$, and $0.38(p<0.05)$ after 20 -yr smoothing indicating some similarities in the low frequency domain. This reveals some common patterns in spite of 
differences in spatial extension and detrending methods applied in the large scale records. Key multi-centennial variations common to all records are high values associated with a late Medieval Warm Period (1200-1420) a multi-centennial depression between 1420 and 1830, attributed to the LIA, and a recent warming trend (from 1980 onwards). However, the reconstructed $\mathrm{NH}$ temperatures are not very high during the 10th and 11 th centuries and are less sensitive to the Oort solar minimum. At decadal scales, all records show low temperatures in the 1070s, 1300s, 1460s, around 1600, and 1820, and high temperatures in the 1420 s and in the 1570 s.

\section{Conclusions}

A new larch/pine composite chronology is presented, integrating populations from western Alps and providing evidence of Alpine summer temperature variations back to 1000. The Adaptive Regional Growth Curve method is used to preserve both low to high frequency information from the data. Instrumental measurements from the HISTALP high temperatures time series back to 1818 are used for calibration and low-elevation series were used for verification. The new record correlates with high-elevation JJA temperatures back to 1818 , but indicates discrepancies between "cooler" proxy-inferred and "warmer" instrumental values prior to 1850. The multidecadal to centennial variations properly match with solar forcings particularly during solar minima and some annual to decadal coolings are related to volcanic eruptions especially at the beginning of the 19th century. The record indicates a short Medieval Warm Period with warmer conditions beginning as late as the early 13th. The LIA is particularly cold between 1420 and 1720 with a mean summer temperature of $-0.80^{\circ} \mathrm{C}$ compared to the $1901-2000$ reference period. After 1720, temperatures increase with distinct depressions during the 1810-20s, the 1910s, and 1970s. According to this regional analysis, the last decade of the 20th is the warmest period over the past millennium: $+0.9^{\circ} \mathrm{C}$ (compared to the 1901-2000 reference period). The amplitude of this warming compared to the previous period is even higher. It largely exceeds the warming reconstructed for the Medieval Warm Period in both its amplitude and abruptness. This particular feature (outstanding intense and rapid warming) is consistent with the fact that it might be attributed to the contribution of anthropogenic greenhouse gases and aerosols. These periods are seen in Alpine, European or hemispheric reconstructions but also in independent proxies (historical archives, speleothems) indicating the relevance of this new record and the Alps to large-scale studies of global climate change.
Acknowledgements. This research has been supported by the program ESCARSEL (2007-2010), "Evolution Séculaire du Climat dans les régions circum-Atlantiques et Réponse de Systèmes Eco-Lacustres" funded by the French ANR "Vulnérabilité: milieux et climat". We are grateful to 2 anonymous referees who provided detailed comments and suggestions that greatly helped to clarify the points discussed here.

Edited by: H. Goosse

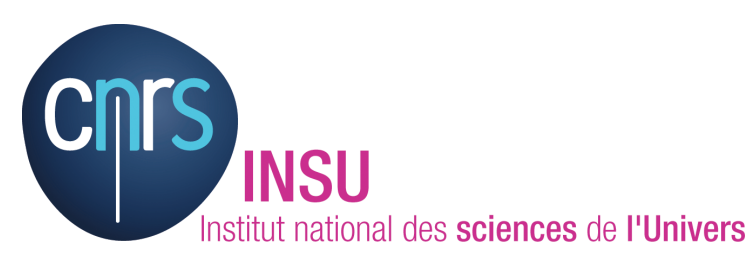

The publication of this article is financed by CNRS-INSU.

\section{References}

Anderson, T. L., Charlson, R. J., Schwartz, S. E., Knutti, R., Boucher, O., Rodhe, H., and Heintzenberg, J.: Climate forcing by aerosols - A hazy picture, Science, 302, 1679-1681, 2003.

Auer, I., Böhm, R., Jurkovi, A., Lipa, W., Orlik, A., Potzmann, R., Schöner, W., Ungersböck, M., Matulla, C., Briffa, K., Jones, P., Efthymiadis, D., Brunetti, M., Nanni, T., Maugeri, M., Mercalli, L., Mestre, O., Moisselin, J.-M., Begert, M., MüllerWestermeier, G., Kveton, V., Bochnicek, O., Stastny, P., Lapin, M., Szalai, S., Szentimrey, T., Cegnar, T., Dolinar, M., GajicCapka, M., Zaninovic, K., Majstorovic, Z., and Nieplova, E.: HISTALP - historical instrumental climatological surface time series of the Greater Alpine Region, Int. J. Climatol., 27, 17-46, 2007.

Bard, E., Raisbeck, G., Yiou, F., and Jouzel, J.: Comment on "Solar activity during the last $1000 \mathrm{yr}$ inferred from radionuclide records" by Muscheler et al. (2007), Quaternary Sci. Rev., 26, 2301-2308, 2007.

Becker, M.: The role of climate on present and past vitality of silver fir in the Vosges mountains of northern France, Can. J. Forest Res., 19, 1110-1117, 1989.

Begert, M., Schlegel T., and Kirchhofer W.: Homogeneous temperature and precipitation series of Switzerland for 1864 to 2000 , Int. J. Climatol., 25, 65-80, 2005.

Böhm, R., Auer, L., Brunetti, M., Maugeri, M., Nanni, D., and Schöner, W.: Regional temperature variability in the European Alps: 1760-1998 from homogenized instrumental time series, Int. J. Climatol., 21, 1779-1801, 2001.

Brázdil, R., Pfister, C., Wanner, H., Von Storch, H., and Luterbacher, J.: Historical climatology in Europe-State of the art, Climate Change, 70, 363-430, 2005.

Briffa, K. R., Jones, P. D., Bartholin, T. S., Eckstein, D., Schweingruber, F. H., Karlén, W., Zetterberg, P., and Eronen, M.: Fennoscandian summers from AD 500 - temperature-changes on short and long timescales, Clim. Dynam., 7, 111-119, 1992.

Briffa, K. R., Schweingruber, F. H., Jones, P. D., Osborn, T. J., Harris, I. C., Shiyatov, S. G., Vaganov, E. A., and Grudd, H.: 
"Trees tell of past climates: but are they speaking less clearly today?", Philos. T. Roy. Soc. B., 353, 65-73, 1998.

Briffa, K. R., Osborn, T. J., Schweingruber, F. H., Harris, I. C., Jones, P. D., Shiyatov, S. G., and Vaganov, E. A.: Low-frequency temperature variations from a northern tree-ring density network, J. Geophys. Res., 106, 2929-2941, 2001.

Brunetti, M., Maugeri, M., Monti, F., and Nanni, T.: Temperature and precipitation variability in Italy in the last two centuries from homogenised instrumental time series, Int. J. Climatol., 26, 345381, 2006.

Büntgen, U., Esper, J., Frank, D. C., Nicolussi, K., and Schmidhalter, M.: A 1052-year tree-ring proxy of Alpine summer temperatures, Clim. Dynam., 25, 141-153, 2005.

Büntgen, U., Frank, D. C., Nievergelt, D., and Esper, J.: Summer temperature variations in the European Alps, AD 755-2004, J. Climate, 19, 5606-5623, 2006a.

Büntgen, U., Bellwald, I., Kalbermatten, H., Schmidhalter, M., Freund, H., Frank, D.C., Bellwald, W., Neuwirth, B., Nüsser, M., and Esper, J.: 700 years of settlement and building history in the Lötschental/Switzerland, Erdkunde, 60/2, 96-112, 2006b.

Büntgen, U., Frank, D., Wilson, R., and Esper, J.: A test for treering divergence in the European Alps, Glob. Change Biol., 14, 2443-2453, 2008.

Carrer, M. and Urbinati, C.: Age-dependent tree-ring growth responses to climate in Larix decidua and Pinus cembra., Ecology, 85, 730-740, 2004.

Carrer, M. and Urbinati, C.: Long-term change in the sensitivity of treering growth to climate forcing in Larix decidua, New Phytol., 170, 861-872, 2006.

Casty, C., Wanner, H., Luterbacher, J., Esper, J., and Böhm, R.: Temperature and precipitation variability in the European Alps since 1500, Int. J. Climatol., 25, 1855-1880, 2005.

Chuine, I., Yiou, P., Viovy, N., Seguin, B., Daux, V., and LeRoy Ladurie, E.: Grape ripening as an indicator of past climate, Nature, 432, 289-290, 2004.

Cook, E. and Kairiukstis, L.: Methods of dendrochronology, Kluwer, Dordrecht, 1990.

Cook, E. R., Briffa, K. R., and Jones, P. D.: Spatial regression methods in dendroclimatology: A review and comparison of two techniques, Int. J. Climatol., 14, 379-402, 1994.

Cook, E. R., D’Arrigo, R. D., and Mann, M. E.: A well-verified, multiproxy reconstruction of the Winter North Atlantic Oscillation Index since AD 1400, J. Climate, 15, 1754-1764, 2002.

Crowley, T. J.: Causes of climate change over the past 1000 years, Science, 295, 270-277, 2000.

D'Arrigo, R., Wilson, R., and Jacoby, G.: On the long-term context for late twentieth century warming, J. Geophys. Res., 111, D03103, doi:10.1029/2005JD006352, 2006.

Dai, J., Mosley-Thompson, E., and Thompson, L. G.: Ice core evidence for an explosive tropical volcanic eruption 6 years preceding Tambora, J. Geophys. Res., 96, 17361-17366, 1991.

Eddy, J. A.: The maunder minimum, Science, 192, 1189-1202, 1976.

Efron, B.: Bootstrap methods: another look at the jackknife, The Annals of Statistics, 7, 1-26, 1979.

Esper, J., Cook, E. R., and Schweingruber, F. H.: Low-frequency signals in long tree-ring chronologies for reconstructing past temperature variability, Science, 295, 2250-2253, 2002.

Esper, J., Niederer, R., Bebi, P., and Frank, D: Climate signal age ef- fects - Evidence from young and old trees in the Swiss Engadin, Forest Ecol. Manag., 255, 3783-3789, 2008.

Etien, N., Daux, V., Masson-Delmotte, V., Stievenard, M., Bernard, V., Durost, S., Guillemin, M. T., Mestre, O., and Pierre, M.: A bi-proxy reconstruction of Fontainebleau (France) growing season temperature from AD 1596 to 2000, Clim. Past, 4, 91-106, doi:10.5194/cp-4-91-2008, 2008.

Folland, C. K., Rayner, N. A., Brown, S. J., Smith, T. M., Shen, S. S. P., Parker, D. E., Macadam, I., Jones, P. D., Jones, R. N., Nicholls, N., and Sexton, D. M. H.: Global temperature change and its uncertainties since 1861, J. Geophys. Res., 28, 26212624, 2001.

Frank, D. and Esper, J.: Temperature reconstructions and comparisons with instrumental data from a tree-ring network for the European Alps, Int. J. Climatol., 25, 1437-1454, 2005.

Frank, D., Büntgen, U., Böhm, R., Maugeri, M., and Esper, J.: Warmer early instrumental measurements versus colder reconstructed temperatures: shooting at a moving target, Quaternary Sci. Rev., 28, 3298-3310, 2007a.

Frank, D., Esper, J., and Cook, E. R.: Adjustment for proxy number and coherence in a large-scale temperature reconstruction, Geophys. Res., 34, doi:10.1029/2007GL030571, 2007 b.

Fritts, H. C.: Tree Rings and Climate, Academic Press, 1976.

García de Cortázar-Atauri, I., Daux, V., Garnier, E., Yiou, P., Viovy, N., Seguin, B., Boursiquot, J.M., Parker, A.K., van Leeuwen, C., and Chuine I.: Climate reconstructions from grape harvest dates: Methodology and uncertainties, The Holocene, doi:10.1177/0959683609356585, 2010.

Grove, J. M.: The Little Ice Age, Methuen and Co., London, New York, 1988.

Guiot, J.: Methods of calibration, verification and reconstruction, in: Methods of denrochronology, application in the environmental sciences, edited by: Cook, E. and Kairiukstis, L., Dordrecht, International Institute for Applied Systems Analysis, Kluwer Academy Publications, 163-217, 1990.

Guiot, J., Nicault, A., Rathgeber, C., Edouard, J.-L., Guibal, F., Pichard, G., and Till, C.: Last-millennium summer-temperature variations in western Europe based on proxy data, The Holocene, 15, 489-500, 2005.

Harrington, C. D.: The Year without a Summer? World Climate in 1816, Canadian Museum of Nature, Ottawa, 1992.

Holzhauser, H., Magny, M., and Zumbühl, H. J.: Glacier and lakelevel variations in west-central Europe over the last 3500 years, The Holocene, 15, 789-801, 2005.

Hughes, M. K. and Diaz, H. F.: Was there a "Medieval Warm Period" and if so, where and when?, Climatic Change, 26, 109-142, 1994.

Jones, P. D., Osborn, T. J., and Briffa, K. R.: The evolution of climate over the last millennium, Science, 292, 662-666, 2001.

Jones, P. D. and Mann, M. E.: Climate over past millennia, Rev. Geophys., 42, RG2002, doi:10.1029/2003RG000143, 2004.

Lamb, H. H.: Climate: present, past and future, London: Methuen, 1976.

Lachiver, M.: Vins, Vignes et Vignerons: Histoire du Vignoble Français, Fayard, Paris, 1988.

LeRoy Ladurie, E.: Histoire humaine et comparée du climat, Vol 1: Canicules et glaciers XIII-XVIII siècles, Fayard, 740pp., Paris, 2004.

Luterbacher, J., Rickli, R., Xoplaki, E., Tinguely, C., Beck, C., Pfis- 
ter, C., and Wanner, H.: The Late Maunder Minimum (16751715) - A key period for studying decadal scale climate change in Europe, Climate Change, 49, 441-462, 2001.

Luterbacher, J., Xoplaki, E., Dietrich, D., Jones, P. D., Davies, T. D., Portis, D., Gonzalez- Rouco, J. F., von Storch, H., Gyalistras, D., Casty, C., and Wanner, H.: Extending North Atlantic Oscillation reconstructions back to 1500, Atmos. Sci. Lett., 2, 114-124, 2002.

Luterbacher, J., Dietrich, D., Xoplaki, E., Grosjean, M., and Wanner, H.: European seasonal and annual temperature variability, trends, and extremes since 1500, Science, 303, 1499-1504, 2004.

Luterbacher, J., Dietrich, D., Xoplaki, E., Grosjean, M., and Wanner, H.: European Seasonal Temperature Reconstructions. IGBP PAGES/World Data Center for Paleoclimatology Data Contribution Series \# 2006-060. NOAA/NCDC Paleoclimatology Program, Boulder CO, USA, 2006.

Mangini, A., Spoetl, C., and Verdes, P.: Reconstruction of temperature in the Central Alps during the past 2000 year from a d180 stalagmite record, Earth Planet. Sc. Lett., 235, 741-751, 2005.

Mann, M. E., Bradley, R. S., and Hughes, M. K.: Northern Hemisphere temperatures during the past millennium: inferences, uncertainties, and limitations, Geophys. Res. Lett., 26, 759-762, 1999.

Mann, M. E., Gille, E., Bradley, R. S., Hughes, M. K., Overpeck, J. T., Keimig, F. T., and Gross, W.: Global temperature patterns in past centuries: an interactive presentation, Earth Interactions, 4, 1-29, 2000.

Mann, M. E. and Jones, P. D.: Global Surface Temperatures over the Past Two Millennia, Geophys. Res. Lett., 30, doi:10.1029/2003GL017814, 2003.

Mann, M. E.: Clmate over the Past two millennia, Annu. Earth Planet. Sci., 35, 111-136, 2007.

Matulla, C., Auer, I., Böhm, R., Ungersböck, M., Schöner, W., Wagner, S., and Zorita, E.: Outstanding past decadalscale climate events in the Greater Alpine region analysed by 250 years data and model runs, GKSS-Report 2005/4, GKSS Forschungszentrum in der Helmholtz Gemeinschaft, Geesthacht, 2005.

Meehl, G. A., Washington, W. M., Wigley, T. M. L., Arblaster, J. M., and Dai, A.: Solar and greenhouse gas forcing and climate response in the twentieth century, J. Climate, 16, 426-444, 2003.

Meier, N., Rutishauser, T., Pfister, C., Wanner H., and Luterbacher, J.: Grape harvest dates as proxy for Swiss April to August temperature reconstructions back to AD 1480, Geophys. Res. Lett., 34, L20705, doi:10.1029/2007GL031381, 2007.

Moberg, A., Alexandersson, H., Bergström, H., and Jones, P. D.: Were Southern Swedish summer temperatures before 1860 as warm as measured?, Int. J. Climatol., 23, 1495-1521, 2003.

Moberg, A. D., Sonechkin, M., Holmgren, K., Datsenko, N. M., and Karlen, W.: Highly variable Northern Hemisphere temperatures reconstructed from low- and high-resolution proxy data, Nature, 433, 613-617, 2005.

Mitchell, T. D., Hulme, M., and New, M.: Climate data for political areas, Area, 34, 109-112, 2002.

Mitchell, T. D. and Jones, P.: An improved method of constructing a database of monthly climate observations and associated highresolution grids, Int. J. Climatol., 25, 693-712, 2005.

New, M., Hulme, M., and Jones, P. D.: Representing twentiethcentury space - time climate variability. Part II: development of
1901-96 monthly grids of terrestrial surface climate, J. Climate, 13, 2217-2238, 2000.

Ni, F., Cavazos, T., Hughes, M. K., Combrie, A., and Funkhouser, G.: Cool-season precipitation in the Southwestern USA since $\mathrm{AD}$ 1000: comparison of linear and non linear techniques for reconstruction, Int. J. Climatol., 22, 1645-1662, 2002.

Nicault, A., Alleaume, S., Brewer, S., Carrer, M., Nola, P., and Guiot, J.: Mediterranean drought fluctuation during the last 500 years based on tree-ring data, Clim. Dynam., 31, 227-245, 2008.

Nicault, A., Guiot, J., Edouard, J.-L., and Brewer, S.: Preserving long-term fluctuations in standardization of tree-ring series by the Adaptative Regional Growth Curve (ARGC), Dendrochronologia, 28, 1-12, 2010.

Oerlemans, J.: Extracting a climate signal from 169 glacier records, Science, 308, 675-677, 2005.

Oppenheimer, C.: Climatic, environmental and human consequences of the largest known historic eruption: Tambora volcano (Indonesia) 1815, Prog. Phys. Geog., 27, 230-259, 2003.

Pauling, A., Luterbacher, J., Casty C., and Wanner, H.: Five hundred years of gridded high-resolution precipitation reconstructions over Europe and the connection to large-scale circulation, Clim. Dynam., 26, 387-405, 2006.

Pfister, C.: Monthly temperature and precipitation patterns in Central Europe from 1525 to the present. A methodology for quantifying man made evidence on weather and climate, in: Climate since $1500 \mathrm{AD}$, edited by: Bradley, R. S. and Jones, P. D., London, 118-143, 1992.

Pfister, C., Kington, J., Kleinlogel, G., Schuele, H., and Siffert, E.: The creation of highresolution spatio-temporal reconstructions of past climate from direct meteorological observations and proxy data, Methodological considerations and results, in: Climate in Europe 1675-1715, edited by: Frenzel, B., Pfister, C., and Glaeser, B., 1994.

Pfister, C.: Wetternachhersage, 500 Jahre Klimavariationen und Naturkatastrophen 1496-1995, Haupt Verlag, 1999.

Rathgeber, C., Guiot, J., Roche, P., and Tessier, L.: Augmentation de productivité du chêne pubescent en région méditerranéenne française, Ann. Sci. Forest., 56, 201-209, 1999.

Richman, M. B.: Rotation of principal components, J. Climatol., 6, 293-335, 1986.

Robock, A.: Review of year without a summer? World climate in 1816, Climate Change, 26, 105-108, 1994.

Schneider, T.: Analysis of incomplete climate data: estimation of mean values and covariance matrices and imputation of missing values, J. Climate, 14, 853-871, 2001.

Shindell, D. T., Schmidt, G. A., Mann, M. E., Rind, D., and Waple, A.: Solar forcing of regional climate change during the Maunder Minimum, Science, 294, 2149-2152, 2001.

Sigurdsson, H. and Carey, S.: Plinian and co-ignimbrite tephra fall from the 1815 eruption of Tambora volcano, B. Volcanol., 51, 243-270, 1989.

Wanner, H., Pfister, C., Brazdil, R., Frich, P., and Frydendah, K.: Wintertime European circulation patterns during the late Maunder minimum cooling period [1675-1704], Theor. Appl. Climatol., 51, 167-175, 1995.

Wigley, T. M. L., Briffa, K. R., and Jones, P. D.: On the average of value of correlated time series, with applications in dendroclimatology and hydrometeorology, J. Clim. Appl. Meteorol., 23, 201-213, 1984. 
Woodhouse, C. A.: Artificial neural networks and dendroclimatic reconstructions: an example from the Front Range, Colorado, USA, The Holocene, 9, 521-529, 1999.

Xoplaki, E., Luterbacher, J., Paeth, H., Dietrich, D., Steiner, N., Grosjean, M., and Wanner, H.: European spring and autumn temperature variability and change of extremes over the last half millennium, Geophys. Res. Lett., 32, L15713, doi:10.1029/2005GL023424, 2005.
Zumbühl, H. J., Steiner, D., and Nussbaumer, S. U.: 19th century glacier representations and fluctuations in the central and western European Alps: an interdisciplinary approach, Global Planet. Change, 60, 42-57, 2008. 